Universidade Estadual Paulista

"Júlio de Mesquita Filho"

Faculdade de Medicina de Botucatu

\title{
Efeito da suplementação nutricional com cogumelo A. blazei sobre a infecção experimental murina aguda por Paracoccidioides brasiliensis
}

\author{
Kattya Christina Paes Jorge
}

Orientador: Prof. Dr. Ramon Kaneno

Co-orientadora: Prof ${ }^{a}$ Dra Ângela Maria V. C. Soares

Dissertação apresentada ao Programa de Pós-Graduação em Doenças Tropicais da Faculdade de Medicina de Botucatu - UNESP, para obtenção do Título de Mestre em Doenças Tropicais

Botucatu - 2010 
"Para realizar grandes conquistas, devemos não apenas agir, mas também sonhar; não apenas planejar, mas também acreditar."

(Anatole France) 
Dedicatória, Homenagem e

Agradecimentos 


\section{Dedicatória}

Dedico este trabalho

A minha querida filha Júlia

Luz do meu caminho, razão da minha vida, seu sorriso acalma qualquer angustia, espanta qualquer tristeza e me dá forças para jamais desistir. Obrigada por você existir e deixar a vida de sua mamãe cada dia mais feliz e desculpa pelos momentos de ausência. A mamamãe Te Ama Muito...

"A medida do amor é amar sem medida."

(Santo Agostinho)

\section{Ao meu marido querido Marcilio}

A pessoa que Deus preparou para seguir comigo este caminho. Que me ajudou em todos os momentos. Obrigada pelo amor, compreensão, paciência e apoio. Estar ao seu lado faz com que me sinta capaz de realizar todos os meus sonhos. Sua força me faz superar qualquer dificuldade. Amo Você Muitão...

"A vida nos ensinou que o amor não consiste em olhar um para o outro, mas sim olhar juntos na mesma direção." (Antoine De Saint Exupery)

\section{Aos meus queridos pais Carlos e Alice}

Por me proporcionarem a oportunidade de estudar e por sempre acreditarem em minha capacidade, pelo apoio e compreensão em todas as fases de minha vida. Obrigada pelas muitas vezes que deixaram seus sonhos de lado para me ajudar a conquistar os meus. Esta conquista também e de vocês.

"Viver é acreditar e realizar o impossivel."

(Frases e Pensamentos de Roberto Shinyashiki) 


\section{Homenagem}

\section{Ao meu orientador Prof. Dr. Ramon Kaneno}

Que acreditou em mim e me proporcionou a oportunidade de desenvolver este trabalfo, sempre muito compreensivo, ótimo pesquisador, ético e muito competente. Por ter sido favorecedor e incentivador deste trabalho, por me ajudar a vencer os obstáculos. Muito Obrigada pela valiosa orientação científica, pelos ensinamentos passados que muito contribuíram para meu enriquecimento profissional e pessoal.

"Feliz aquele que transfere o que sabe e aprende o que ensina." (Frases e Pensamentos de Cora Coralina)

"A arte da vida consiste em fazer da vida uma obra de arte."

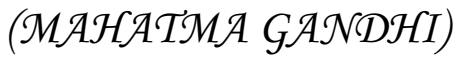




\section{Agradecimentos}

Com muito carinho meus sinceros agradecimentos a todos que participaram comigo nesta caminhada:

À Deus que se faz presente em todos os momentos de minha vida, guiando os meus passos me ajudando a trilhar e seguir o melhor caminho.

Às minhas irmãs queridas Karla e Karen companheiras de todas as horas, amigas $e$ confidentes com quem sei que sempre posso contar, que estão sempre comigo me dando força e torcendo por mim.

Aos meus familiares por todo carinho, apoio e amizade, sempre acreditando em mim.

À minha co-orientadora Profa. Dra. Ângela M. V. C. Soares, pela amizade e apoio na realização deste trabalho, descobri nela muito mais que uma amiga...

A minha querida amiga Michele $\mathcal{A}$. J. Valerio que aceitou o desafio comigo e nunca se abateu perante as dificuldades, sempre foi e será muito mais que uma amiga, que dividimos juntas muitas alegrias e tristezas, e nunca perdemos a alegria de viver intensamente cada passo em nossas vidas.

A minha querida amiga Ana Paula Bordon Graciani que com toda a disposição me ajudou na realização deste trabalho, me mostrou que trabalhando em equipe tudo fica mais fácil, muito mais divertido. Obrigada pelos maravilhosos momentos que passamos juntas.

Ao amigo Helanderson A. Balderramas que me ajudou na realização dos experimentos, sempre muito prestativo, companheiro de todas as horas. 
A minha querida amiga Márjorie de Assis Golim que sempre me inventivou a correr atrás dos meus sonhos, não desistir jamais, e principalmente por saber que não importa a hora sei que sempre posso e poderei contar com você.

Aos docentes do Departamento de Microbiologia e Imunologia, Dr. José Maurício Sforcin, Dra Maria Terezinha Serrão Peraçoli, Dr. Sílvio Luis de Oliveira, Dra Alexandrina Sartori, pela convivência agradável, pela amizade e apoio.

Aos funcionários do Departamento de Microbilogia e Imunologia, Sônia M. Faraldo, Leonice A. Garcia, Luiz H. Alquati e pricipalmente ao Luiz S. dos Santos (Lula), que sempre disposto a ajudar muito colaborou com a realização dos experimentos me auxiliando na manutenção dos animais no Biotério do Departamento de Microbiologia e Imunologia.

Às professoras Dra Alexandrina Sartori e Dra Sueli A. Calvi pelas valiosas sugestões durante o exame de qualificação.

Aos colegas e amigos do Departamento de Microbilogia e Imunologia, que acompanharam nesta caminhada, obrigada pelo carinho e apoio, em especial Guilherme Biondo e Cibele Ferrari.

Aos meu colegas de trabalho Maria Salete Satori, Maria Valéria Morales Dalanezi, Pedro Martos Neto, Maria José Conte, Mari Angela de Toledo Silva, que muito me ajudaram na realização das análises bioquímicas e também pelo companheirismo.

Ao Paulo Cesar Geargete (Biotério de Patologia) pela confecção da ração suplementada para os animais.

Aos Professores Carlos Taborda e Maria José Mendes Giannini pela gp43 gentilmente fornecida para realização dos ensaios 
Aos meus queridos amigos de Laboratório Talita Pompiani Paes de Almeida, Marcos Montanha, Ana Paula Dória, Carlos Eduardo Jorge e Rita Borges dos Santos pelos maravilhosos momentos de descontração no serviço ou fora dele que com certeza deram uma injeção de ânimo para a conclusão deste trabalho.

Aos funcionários da Pós-Graduação da Faculdade de Medicina por toda a dedicação, auxílio e amizade.

As bibliotecárias pela disposição e realização da ficha catalográfica.

Ao Prof. Dr. Paulo Câmara Marques Pereira, coordenador do Curso de Pós-Graduação em Doenças Tropicais, por sempre estar pronto a ajudar, à Solange, secretária da PósGraduação do Departamento de Doenças Tropicais, pelo apoio e auxílio constantes.

"Um verdadeiro amigo é aquele que entra quando o resto do mundo sai." (Walter Winchell) 
Sumário 


\section{Sumário}

I - Resumo 13

$\begin{array}{ll}\text { II - Abstract } & 16\end{array}$

III - Introdução $\quad 19$

IV - Objetivos 34

V - Delineamento Experimental 36

VI - Material e Métodos 36

1 - Animais 36

2 - Cultivo do P. brasiliensis $\quad 37$

3 - Preparo do inóculo e determinação da viabilidade do P. brasiliensis 37

4 - Infecção e tratamento 38

5 - Preparo da ração suplementada 38

6 - Recuperação de fungos em órgãos-alvo 39

7 - Parâmetros bioquímicos $\quad 39$

8 - Dosagem de IL-6, TNF- $\alpha$, IL-10, IL-4 e IFN- $\gamma$

9 - Atividade linfoproliferativa 41

10 - Análise Estatística 42

VII - Resultados

1 - Peso corpóreo e consumo de ração 44

2- Efeito do $A$. blazei sobre a sobrevida dos animais infectados e recuperação de fungos viáveis de órgãos alvo

3- Parâmetros bioquímicos $\quad 49$

$\begin{array}{ll}4 \text { - Atividade Linfoproliferativa } & 55\end{array}$

5 - Efeito da infecção e tratamento dietético sobre o perfil de citocinas do pulmão

6 - Efeito da infecção e tratamento dietético sobre o perfil de citocinas do baço e fígado

VIII - Discussão

IX - Referências Bibliográficas $\quad 73$

$X$ - Anexos 81 
Resumo 


\section{I - Resumo}

A paracoccidioidomicose é uma das mais importantes micoses sistêmicas da América Latina e a resistência ao agente é fortemente dependente da resposta imune do hospedeiro. Devido à rica composição nutricional e suas propriedades medicinais o cogumelo comestível Agaricus blazei é amplamente utilizado na medicina tradicional. Dessa forma, o objetivo do presente trabalho foi avaliar se a suplementação nutricional de camundongos infectados por $P$. brasiliensis, com o cogumelo $A$. blazei, contribui para a manutenção de seu estado nutricional e de sua competência imunológica. Para isso, camundongos BALB/c foram infectados por via intratraqueal com leveduras de $\mathrm{Pb} 18$ e suplementados dieteticamente com o cogumelo acrescentado à ração comercial. Os animais foram sacrificados aos 7 ou 14 dias pós-infecção para avaliar o grau de infecção no pulmão, baço e fígado e do efeito do tratamento sobre a capacidade de resposta imune celular. Os animais infectados apresentaram perda de peso no início da infecção, com recuperação após duas semanas. Os animais infectados e suplementados com ração $15 \%$ tiveram maior perda de peso, bem como menor nível de recuperação em relação ao peso inicial. Os parâmetros bioquímicos indicam que as funções hepáticas e renais sofreram alterações decorrentes da infecção mas os efeitos da suplementação nutricional foram de pouca relevância. O tratamento provocou exacerbação da infecção na fase inicial (7 dias), acompanhada de intensa redução da atividade linfoproliferativa. A resistência dos animais parece restaurada aos 14 dias nos animais que receberam $5 \%$ de cogumelo na ração, observando-se redução de fungos viáveis nos pulmões, restauração da capacidade de resposta proliferativa dos esplenócitos, aumento nos níveis de 
TNF- $\alpha$ e redução de IL-4 nos pulmões e discreto aumento de IFN- $\gamma$ no baço. Em conjunto, nossos resultados sustentam parcialmente nossa hipótese inicial, indicando que a suplementação ajuda os animais a restabelecerem sua resposta imune celular na segunda semana. Entretanto, o cogumelo, quando em excesso (15\%) ou se administrado no início da fase aguda, pode facilitar a instalação do agente infeccioso e determinar o estabelecimento de uma doença mais grave. 
A6stract 


\section{II - Abstract}

Paracoccidioides is one of the main systemic mycosis in Latin America and the host resistance to the fungus Paracoccidioides brasiliensis, is strongly dependent on the immune responsiveness. Due to it rich nutritional composition and medicinal properties, the edible mushroom Agaricus blazei is widely used as traditional medicine. Then, our goal was to investigate whether the nutritional supplementation with $A$. blazei helps $P$. brasiliensis-infected mice to keep their nutritional status and immunocompetence. For this purpose, BALB/c mice were infected for intratracheal route with $\mathrm{Pb} 18$ yeasts and fed with comercial chow supplemented with dried and powdered A. blazei fruiting bodies. Animals were evaluated at the 7th and 14th day on the infection levels, in lung, spleen and liver, and on cellular immunoresponsiveness. Infected mice showed weight loose in the beginning of the infection that was partially restored after 2 weeks. Infected animals, supplemented with $15 \%$ of $A$. blazei showed the higher weight loose, as well as lower restoring levels. Biochemical parameters indicate that the infection itself interfered in the liver and kidney functions but no relevant effect of nutritional supplementation was detected. The treatment induced infection exacerbation at the first week that was followed by intense decrease of lymphoproliferative activity of spleen cells. The resistance of mice against $P$. brasiliensis appears to be restored by the 14 th day in those mice eating feed with $5 \%$ A. blazei. This view is supported by the observation that such animals have lower number of viable fungus inside the lungs than controls (group $\mathrm{Pb}$ ), and also restored the lymphoproliferative activity. We also observed increased levels of TNF- $\alpha$ and decreased levels of IL-4 in the lungs and slight increase of INF- $\gamma$ in the spleen. Altogether, our results partially supported our initial hypothesis, indicating that the 
nutritional supplementation helps restoring the cellular immuneresponsiveness by the second week. However, the excessive supplementation (15\%) or the administration during the early acute phase can enhance the infection and drive it to a severe disease. 
Introdução 


\section{III - Introdução}

A paracoccidioidomicose (PCM) é uma micose sistêmica que se manifesta endemicamente na maioria dos países da América Latina, especialmente no Brasil, Argentina, Colômbia e Venezuela [1]. Seu agente etiológico, o Paracoccidioides brasiliensis, é um fungo imperfeito e dimórfico, que se apresenta sob a forma de micélio à temperatura ambiente e na forma de levedura in vivo e quando cultivado a $3^{\circ} \circ \mathrm{C}$ em meios de cultura enriquecidos [2] [3] [4].

A temperatura parece ser o fator determinante do dimorfismo desse fungo [5], embora fatores nutricionais do meio de crescimento possam estar envolvidos na regulação desse fenômeno [6].

A doença afeta principalmente trabalhadores rurais, que estão constantemente em contato com a vegetação e o solo. Na forma aguda da doença, jovens de ambos os sexos são afetados na mesma proporção, porém, na forma crônica do adulto há predominância de homens em relação às mulheres afetadas, sendo esse processo relacionado a um efeito protetor promovido pelos hormônios femininos. De fato, estudos in vitro demonstram que estrógenos inibem a transformação de micélios ou conídios em leveduras, interferindo na instalação da infecção [7] [8] . Paralelamente, foi demonstrada a presença de receptores para estrógeno tanto na fase micelial como na leveduriforme do fungo [9] [10].

Evidências epidemiológicas e experimentais sugerem que a infecção natural se inicia após inalação dos conídios ou fragmentos do micélio presentes em água, plantas e solo, que penetrariam no hospedeiro pelas vias aéreas e, ao atingirem o pulmão, iniciam a transformação em leveduras com múltiplos brotamentos após 12-18h, provocando o chamado complexo primário pulmonar 
[11] [12]. Desse modo, lesões primárias ocorrem com maior freqüência nesse órgão, dando origem a uma infecção subclínica. Essa infecção pode manter-se latente, caracterizando a paracoccidiodomicose-infecção, identificada pela ausência de sinais ou sintomas clínicos, embora ocorra o desenvolvimento de uma resposta imune específica, que pode ser evidenciada pela reação de hipersensibilidade tardia no teste intradérmico com paracoccidiocodina $(\mathrm{HT})$ [11] [13].

A infecção pode progredir para a paracoccidiocomicose-doença com disseminação para outros órgãos por via linfohematogênica [14]. Clinicamente, podem ser diferenciadas duas formas de apresentação da doença, conhecidas como infecção aguda e crônica. A forma aguda da doença, também referida como forma juvenil, por afetar preferencialmente indivíduos jovens, é considerada a mais grave e de evolução rápida, caracterizando-se especialmente pelo envolvimento do sistema fagocítico-monocitário e podendo afetar baço, fígado, linfonodo e medula óssea. A forma crônica da doença corresponde a mais de 90\% dos casos e atinge, com mais freqüência, indivíduos adultos que sofrem instalação lenta e gradual e duração prolongada, apresentando amplo espectro de manifestações. Observa-se alta freqüência de dano pulmonar e o microrganismo pode disseminar-se para outros órgãos e tecidos, formando lesões secundárias nas mucosas, pele, linfonodos e glândulas adrenais [15].

Vários fatores podem contribuir para o estabelecimento da infecção, disseminação do agente infeccioso e gravidade da doença, destacando-se a virulência da amostra infectante, a carga de partículas infectantes e os fatores ligados ao hospedeiro, como idade, sexo, bagagem genética, estado nutricional e capacidade de desenvolver uma resposta imunológica eficiente [7] [16]. Em 
relação a este último fator, estudos clínicos e experimentais têm sugerido a interação entre mecanismos específicos e inespecíficos de defesa na determinação da resistência ao P. brasiliensis [17] [18] [19] [20].

Tanto nas primeiras fases da infecção, durante o desenvolvimento de uma resposta imune inata, quanto durante a resposta imune especifica, monócitos e macrófagos desempenham um papel efetor essencial induzindo uma resposta inflamatória ou atuando diretamente contra o fungo. No entanto, os estudos deixam clara a importância de um processo de ativação para que essas células exerçam essas atividades. Trabalhos têm mostrado que esse processo depende do contato das células com citocinas como o IFN- $\gamma$ e TNF- $\alpha$. Nesse sentido, observou-se que macrófagos peritoneais e pulmonares de camundongos normais não ativados in vitro, são incapazes de limitar a multiplicação de leveduras do $P$. brasiliensis fagocitadas. No entanto, após o processo de ativação com IFN- $\gamma$, essa células adquirem capacidade de destruir os fungos [21]. Cano et al. [22] verificaram que macrófagos cultivados em presença de citocinas obtidas de células de baço de animais imunizados aumentaram a sua capacidade de destruir conídios, assim como inibiram a transformação de conídios em leveduras [23].

No que se refere às células humanas, os resultados revelaram que monócitos e macrófagos de indivíduos normais quando ativados por IFN- $\gamma$ inibem o crescimento intracelular do $P$. brasiliensis [24]. Outros trabalhos mostraram que a pré-incubação de monócitos com IFN- $\gamma$ não induz essas células a uma atividade fungicida eficiente contra cepa virulenta do $P$. brasiliensis. Essa atividade é adquirida somente após a pré-incubação com TNF- $\alpha$ ou TNF- $\alpha$ mais IFN- $\gamma$ [25] ou GM-CSF [26]. 
Quando as células são desafiadas com cepa de baixa virulência, a préativação apenas com IFN- $\gamma$ é suficiente para aquisição de uma atividade fungicida eficiente, demonstrando que na dependência da cepa utilizada, o processo de ativação das células fagocitárias pode necessitar de sinais dados por diferentes citocinas.

Em relação aos mecanismos através dos quais os monócitos e macrófagos ativados exercem sua atividade, estudos demonstraram que a atividade fungicida de monócitos humanos ativados com TNF envolve a geração de metabólitos do oxigênio como a $\mathrm{H}_{2} \mathrm{O}_{2}$ [27]. A atividade antifúngica de macrófagos murinos ativados com IFN- $\gamma$ envolve a participação dos metabólitos do nitrogênio como o $\mathrm{NO}$ [28]. No entanto, trabalho mais recente demonstrou que tanto $\mathrm{H}_{2} \mathrm{O}_{2}$ como $\mathrm{O}$ NO participam da atividade fungicida de macrófagos murinos ativados com TNF ou IFN [29].

É importante destacar que o processo de ativação das células fagocitárias já deve ocorrer durante o desenvolvimento de uma resposta inata contra o fungo. As fontes das principais citocinas envolvidas, o IFN- $\gamma$ e TNF- $\alpha$, nesta fase, seriam as células NK para o IFN- $\gamma$ [30] [31] ou os próprios macrófagos alveolares ativados pelo contato com o fungo, no caso do TNF. Segundo Figueiredo et al. [32], tanto cepas de $P$. brasiliensis quanto frações da parede celular, ricas em $\beta$-glucanas são capazes de induzir níveis elevados de TNF- $\alpha$, sendo possível sua detecção em soro de camundongos inoculados por via intraperitoneal com o fungo. As frações e a $\beta$-glucana purificada estimularam a secreção in vitro de TNF- $\alpha$ por macrófagos murinos, sugerindo que essa citocina é produzida em resposta ao $P$. brasiliensis e regulada por vários constituintes da parede celular do fungo. Calvi et al. [25], verificaram que a produção de TNF- $\alpha$ por monócitos humanos, 
infectados in vitro com a cepa de menor virulência ( $\mathrm{Pb} 265)$, induziu níveis mais elevados de TNF- $\alpha$ em comparação à cepa virulenta ( $\mathrm{Pb} 18)$. Além disso, níveis mais elevados dessa citocina apresentaram correlação com a maior atividade fungicida dos monócitos, demonstrando a importância do TNF- $\alpha$ nesse mecanismo. Assim, os níveis dessa citocina poderiam variar na dependência da virulência ou da composição da parede celular da cepa com a qual o indivíduo entra em contato, e consequentemente interferir na evolução da doença. A incubação de monócitos humanos com IFN- $\gamma$ mais fração de parede do P.brasiliensis rica em $\beta$-glucana, induziu essas células a uma maior produção de TNF- $\alpha$ com consequente aumento da atividade fungicida [33].

Durante a evolução da infecção, as citocinas ativadoras devem ser geradas por elementos da resposta imune adaptativa, como os linfócitos $\mathrm{CD}_{4}$ Th1. No entanto, estudos em pacientes e modelos experimentais têm demonstrado que essa resposta encontra-se muito deficiente. Neste contexto, os primeiros estudos referentes à avaliação da resposta imune celular e humoral na doença mostraram de uma forma bastante clara que os pacientes apresentam diferentes graus de comprometimento da resposta imune celular, variando desde a total anergia até respostas aparentemente preservadas [34] [35] [36] [37] [38] [39]. O maior grau de anergia é geralmente observado por ocasião do diagnóstico, com tendência à normalização da resposta com a evolução do tratamento [36]. Em relação às formas clínicas demonstrou-se que o comprometimento da resposta imune celular é mais intenso na forma aguda do que na forma crônica da doença [35]. De forma semelhante, uma acentuada depressão da resposta imune celular é detectada em camundongos suscetíveis à infecção [40] [41]. Ao contrário da resposta imune celular, observa-se exacerbação da resposta humoral, justamente nas formas 
mais graves da doença humana [42] e em camundongos suscetíveis à infecção [17] [43] [44]. Trabalhos posteriores aprofundando os estudos sobre esse desequilíbrio da resposta imune na paracoccidioidomicose mostraram que pacientes com a forma juvenil apresentam produção aumentada de $\lg _{4}$, enquanto pacientes com a forma crônica apresentam níveis mais altos de $\lg \mathrm{G}_{1}$. $\mathrm{Na}$ foram juvenil, além de $\lg _{4}$, ocorre produção aumentada de $\lg \mathrm{E}$, $\lg \mathrm{A}$, eosinofilia periférica e baixos níveis de IL-8, [45] [46], sugerindo que na paracoccidioidomicose existe predominância de uma resposta do tipo $\mathrm{TH}_{2}$, resultando nas formas mais graves e disseminadas da doença. Confirmando esses dados, animais sensíveis à infecção apresentam altos níveis de anticorpos $\lg A$, $\lg M, \lg G_{1}$ e $\lg G_{2 b}$ específicos para o fungo [17] [43] [44]. Reforçando os dados de sublasse de anticorpos, estudos sobre o padrão de citocinas caracterizaram que o grupo de indivíduos com parococcidiodomicose-infecção apresenta resposta imune associada ao padrão $\mathrm{TH}_{1}$, com elevada resposta linfoproliferativa a antígenos do fungo, teste cutâneo de HT positivo, ausência de anticorpos e níveis indetectáveis de IL-4, IL-5 e IL-10, com maior produção de IFN- $\gamma$. No entanto, pacientes com a forma juvenil, apresentaram depressão da resposta linfoproliferativa e níveis mais altos de IL-4 e IL-5, citocinas representativas do padrão $\mathrm{TH} 2$, quando comparados aos indivíduos somente infectados e àqueles com a forma crônica da doença [13].

Outros trabalhos reforçam esses achados demonstrando que pacientes com paracoccidiodomicose produzem baixos níveis de IL-2 e IFN- $\gamma$, mas altos níveis de IL-10, associados à depressão da resposta imune celular [47] assim como altos níveis de IL-4, IL-5 e IL-1ß [48]. Outros estudos ainda mostraram que os pacientes liberam baixas concentrações de IL-12 [49] assim como expressam 
baixos níveis dos receptores para essa citocina [50]. Os trabalhos com animais de experimentação, mais uma vez reforçam os achados humanos. Os suscetíveis liberam um padrão de citocinas do tipo $\mathrm{TH}_{2}$ e os resistentes $\mathrm{TH}_{1}$ [17] [51] [52] [53] [54].

Além de polarização para uma resposta do tipo $\mathrm{TH}_{2}$, outros mecanismos podem estar envolvidos na depressão da resposta imune celular na paracoccidioidomicose. Particularmente em pacientes com a forma crônica, essa depressão pode ser atribuída à presença de células $T$ reguladoras $C D_{4}{ }^{+} C D_{25}{ }^{+}$ [55]. Outros estudos têm mostrado uma associação entre baixa capacidade de resposta de células $\mathrm{T}$ de pacientes com aumento na expressão de enzimas indutoras de apoptose [56], assim como alta expressão de moléculas de superfície celular relacionadas a esse processo como FAS-FASL. A expressão de moléculas coestimulatórias responsáveis pelo envio de sinais de desativação das células T como a CTLA-4 também tem sido associada à ausência de resposta de células T aos antígenos fúngicos [57].

Em conjunto, os resultados relatados acima, mostram a necessidade de se estudar agentes com potencial efeito modulador da resposta imune, que poderiam reverter o quadro de imunossupressão característico da paracoccidioidomicose, visando interferências futuras nos pacientes.

Outro fator anteriormente citado, que pode interferir na evolução da infecção pelo $P$. brasiliensis é o estado nutricional do hospedeiro, possivelmente em decorrência do seu efeito sobre o funcionamento do sistema imune. Assim, uma variedade de nutrientes como oligoelementos ( $\mathrm{Zn}, \mathrm{Cu}, \mathrm{Se})$ e o equilíbrio protéico-calórico [58] são considerados fundamentais para a manutenção da homeostase imunológica. Além disso, determinados alimentos ou suplementos 
nutricionais podem aumentar a capacidade de resposta imune do hospedeiro, facilitando sua resposta e resistência à agentes patogênicos encontrados no meio. Tais alimentos são referidos como funcionais ou nutricêuticos, devido a sua capacidade de modular a função de órgãos ou sistemas específicos.

Entre os alimentos nutricêuticos podemos destacar os cogumelos comestíveis e medicinais, cujos componentes bioativos possuem propriedades imunomoduladoras com capacidade potencial de interferir no curso das doenças. Consumo de cogumelos com fins terapêuticos/profiláticos remonta a milhares de anos [59], sendo encontrados em sua composição proteínas, carboidratos, gorduras, fibras, minerais, vitaminas, compostos bioativos [59] e complexos polissacarídicos que apresentam efeitos antitumorais e imunomodulatórios [60]. Popularmente, são empregados no tratamento e prevenção de doenças de caráter crônico como o câncer, a aids, diabetes, hiperlipidemia, aterosclerose e hepatites crônicas [59] [61] [62].

Entre os cogumelos medicinais, destaca-se o Agaricus blazei, popularmente conhecido como cogumelo-do-sol $\circledast$, um basidiomiceto que apresenta excelente valor nutricional, contendo proteínas, ácidos graxos, fibras, açúcares, minerais como $\mathrm{P}, \mathrm{Fe}, \mathrm{Ca}, \mathrm{Zn}, \mathrm{Cu}, \mathrm{Mn}$ e vitaminas $\left(\mathrm{B}_{1}, \mathrm{~B}_{2}, \mathrm{C}, \mathrm{K}, \mathrm{D}\right.$, niancina entre outras) [63]. Este cogumelo foi descoberto no sul do Estado de São Paulo (Mata Atlântica) no final dos anos 60 e os primeiros estudos sobre suas propriedades medicinais foram realizados no Japão, no início da década de 70 . Embora o Japão e a China figurem como os principais produtores de A. blazei, o Brasil continua a ser um dos principais fornecedores para o mercado mundial, com produção crescente em diversos Estados. 
Os estudos experimentais têm demonstrado a ação antimutagênica e imunomoduladora desse cogumelo [59] [63] [64] [65]. Suas propriedades foram estudadas em vários modelos experimentais [59], demonstrando-se que o cogumelo apresenta complexos protéico-polissacarídicos com cadeias simples de $(1 \rightarrow 6)$ - $\beta$-glicopiranosil $(43,3 \%)$ e de proteínas $(50,2 \%)$, com propriedades imunoestimulantes [63]. Assim, produtos do cogumelo A. blazei, especialmente as $\beta$-glucanas, têm a capacidade de estimular mecanismos imunológicos como a atividade fagocítica de macrófagos [66], atividade "natural killer" [65] [66] e de células T citolíticas [67] em camundongos.

Há relatos de que o $A$. blazei promove ativação e expansão clonal de linfócitos T [68] e de que animais tratados com frações extraídas em água quente mostram aumento nas percentagens de células $\mathrm{T}\left(\mathrm{CD}_{3}+\right)$, $\mathrm{T}$ auxiliares $\left(\mathrm{CD}_{4}+\right)$ e células $\mathrm{T}$ citolíticas $\left(\mathrm{CD}_{8^{+}}\right)$[69]. Nakajima et al. [70] demonstraram que o extrato solúvel induziu aumento na produção de anticorpos e nas populações de granulócitos, células NK, macrófagos e linfócitos T e B. Fujimiya et al., [71], sugerem que a inibição do desenvolvimento tumoral, atribuído ao cogumelo, deve-se à estimulação da atividade NK e a geração de células citotóxicas específicas. No plano clínico, observou-se que a fração ABMK exerce efeito positivo sobre a atividade citotóxica das células NK de pacientes com câncer ginecológico submetidas à quimioterapia, além de melhorar alguns parâmetros de qualidade de vida associados aos efeitos colaterais do tratamento convencional, como a perda de apetite, alopecia, náusea ou vômito, condições emocionais e perda de tônus muscular [72]. Desse modo, hipotetisamos que polissacarídeos de A. blazei podem ser agentes imunomoduladores efetivos, não apenas da resistência antitumoral, mas também da resposta a agentes infecciosos diversos. 
Apesar da existência de numerosas publicações sobre o efeito do cogumelo e seus produtos em modelos tumorais, o potencial de uso do cogumelo em doenças infecciosas é pouco explorado. Nesse aspecto, observou-se que frações do cogumelo apresentam atividade antiviral, induzindo a secreção de citocinas por macrófagos [69]. Em estudo prévio, observamos que o extrato polissacarídico de $A$. blazei aumenta a atividade fungicida de macrófagos peritoniais murinos contra Candida albicans [73]. Observamos também que a administração de um extrato polissacarídico de $A$ blazei a camundongos infectados com $P$. brasiliensis promove aumento na atividade fungicida de macrófagos peritoniais, aumento na produção de $\mathrm{H}_{2} \mathrm{O}_{2}$ e $\mathrm{NO}$, e interferência na resposta de perfil $\mathrm{Th}_{2}$ induzida pela infecção, reduzindo o número de células produtoras de IL-4 e aumentando o número de células produtoras de IL-12, além de potencializar a produção de IFN- $\gamma$ e TNF- $\alpha$ [74].

O cogumelo também é popularmente consumido para auxiliar no tratamento de várias doenças crônicas incluindo diabetes, hiperlipidemia, aterosclerose e câncer [75] [76] [77]. No entanto, não existem dados epidemiológicos e experimentais sobre os efeitos benéficos deste cogumelo sobre a atividade bioquímica de função renal, hepática, lipídios, glicose e proteínas.

Os aminoácidos provenientes do catabolismo protéico são desaminados com a produção de amônia. Como esse composto é potencialmente tóxico, é convertido em uréia no fígado. O nível de uréia no plasma é afetado pela função renal, conteúdo protéico da dieta e teor do catabolismo protéico, estado de hidratação do paciente e presença de sangramento intestinal. Apesar destas limitações, entretanto, o nível de uréia ainda serve como índice preditivo da insuficiência renal sintomática e no estabelecimento de diagnóstico na distinção 
entre várias causas de insuficiência renal. A creatinina é produzida como resultado da desidratação não-enzimática da creatina muscular. A creatina por sua vez, é sintetizada no fígado, rim e pâncreas e é transportada para as células musculares e cérebro, onde é fosforilada à creatina-fosfato. A creatina e a creatina-fosfato perdem ácido fosfórico e água e se transformam em creatinina, que não é reutilizada no metabolismo corporal, e esse resíduo de creatina é quase inteiramente eliminada por filtração glomerular. Como a velocidade de excreção da creatinina é relativamente constante e a sua produção não é influenciada pelo metabolismo protéico ou outros fatores externos, a concentração da creatinina sérica é uma excelente medida para avaliar a função renal [78].

As enzimas aspartato aminotransferase, AST (TGO) e alanina aminotransferase, ALT (TGP) catalisam a transferência reversível dos grupos amino de um aminoácido para o a-cetoglutarato, formando cetoácido e ácido glutâmico. As aminotransferases estão amplamente distribuídas nos tecidos humanos e a atividade mais elevadas de AST encontram-se no miocárdio, fígado e músculo esquelético, com pequenas quantidades nos rins, pâncreas, baço, cérebro, pulmões e eritrócitos. A AST é encontrada principalmente no citoplasma do hepatócito, enquanto $80 \%$ da AST está presente na mitocôndria. O aumento do teor de AST pode indicar lesão muscular, dentre elas o infarto do miocárdio, enquanto o aumento da ALT indica lesão hepática [78].

A bilirrubina é o principal produto do metabolismo do heme da hemoglobina. Cerca de $70 \%$ a $80 \%$ da bilirrubina são provenientes da destruição dos eritrócitos velhos, $15 \%$ de fontes hepáticas, e o restante é proveniente da destruição de hemácias defeituosas na medula ósse e nos citocromos. A 
hemoglobina é metabolizada no baço e no sistema reticuloendotelial, sendo degradadas em heme e globina, a anel heme é aberto, produzindo ferro livre e biliverdina, que é reduzida a bilirrubina pela enzima biliverdina redutase. Essa bilirrubina recém-formada circula no sangue ligada à albumina sérica e é transportada pelo sistema porta até o fígado, onde penetra no hepatócito. Uma vez dentro do hepatócito, a bilirrubina desliga-se da albumina e forma um complexo protéico com as chamadas proteínas $\mathrm{Y}$ e Z . Logo depois, liga-se a um outro complexo pelos ductos biliares. A bilirrubina eleva-se no soro na presença de lesões hepáticas, obstrução biliar ou quando a velocidade de destruição dos glóbulos vermelhos está aumentada. Assim, a bilirrubina direta está aumentada nas hepatites agudas e crônicas, nas reações tóxicas a várias drogas e nas obstruções do trato biliar [78].

O colesterol é o esterol componente das membranas celulares de mamíferos e precursor de 3 classes de compostos biologicamente ativos, os hormônios esteróides, ácidos biliares e vitamina D. É transportado no sangue principalmente pelas lipoproteínas de densidade baixa (LDL) e os distúrbios no metabolismo do colesterol exercem papel importante na etiologia da doença arterial coronária [78]. O LDL é a classe de lipoproteínas maléficas aos seres humanos, e transportam o colesterol do sítio de síntese, o fígado, até as células de vários outros tecidos. Outra classe de lipoproteína, as de alta densidade (HDL), podem transportar o excesso de colesterol dos tecidos de volta para o fígado, onde é utilizado para a síntese do ácido biliar. As LDL, quando em excesso, são responsáveis pelos depósitos arterioscleróticos nos vasos sanguíneos, formando placas que podem interromper o fluxo sanguíneo normal, favorecendo a ocorrência de doenças cardíacas [78]. 
O triglicerídeo (triacilglicerol) é nome genérico de qualquer tri-éster oriundo da combinação do glicerol com ácidos, especialmente ácidos graxos, no qual as três hidroxilas sofreram condensação carboxílica com os ácidos. São reconhecidos como óleos ou gorduras, produzidos e armazenados no organismo para fins de reserva alimentar. Um triglicerídeo é formado pela união de três ácidos graxos a uma molécula de glicerol, cujas três hidroxilas ligam-se aos radicais carboxílicos dos ácidos graxos. São sintetizados no fígado intestino, sendo as formas mais importantes de armazenamento e transporte de ácidos graxos. Os distúrbios nesta síntese promovem redução do catabolismo dessas partículas, aumentando os níveis de triglicerídeos plasmáticos. São ocasionados pela ingestão excessiva de alimentos ou, mais raramente, por mutação genética de enzimas da via metabólica dos lipídeos [78].

A glicose é a aldohexose mais importante para a manutenção energética do organismo. Em condições normais, a glicose sanguínea (glicemia) é mantida em teores apropriados por meio de vários mecanismos regulatórios. A elevação da glicose circulante provoca a remoção pelo fígado de $70 \%$ da glicose que é então convertida em glicogênio para ser utilizada como fonte energética no jejum. A glicose é normalmente filtrada pelos rins sendo quase totalmente reabsorvida pelos túbulos renais. Em todas as células, a glicose é metabolizada para produzir ATP e fornecer intermediários metabólicos necessários em vários processos biossintéticos [78].

As funções das proteínas plasmáticas incluem transporte, manutenção da pressão osmótica, tamponamento de alterações de $\mathrm{pH}$, imunidade humoral, atividade enzimática, coagulação e resposta de fase aguda. A concentração das 
proteínas é determinada pela velocidade de síntese, velocidade de catabolismo e volume de líquido no qual as proteínas estão distribuídas. A maioria das proteínas são sintetizadas no fígado enquanto algumas são produzidas em outros locais, como imunoglobulinas pelos linfócitos. As proteínas são degradadas através do corpo e os aminoácidos liberados ficam disponíveis para a síntese de proteínas celulares [78].

Assim, considerando, por um lado, a rica composição nutricional e as propriedades imunoestimulantes do cogumelo $A$. blazei, e por outro lado a necessidade de uma resposta imune celular intacta para combater a infecção por $P$. brasiliensis, o presente trabalho foi formulado para testar a hipótese de que a suplementação nutricional de animais com esse cogumelo pode melhorar a resistência à paracoccidioidomicose através da estimulação da resposta imune celular. 
Objetivos 


\section{IV - Objetivos}

O objetivo geral do projeto foi avaliar o impacto da inclusão do cogumelo $A$. blazei na dieta, sobre a infecção experimental murina aguda com o $P$. brasiliensis, avaliando aspectos imunológicos, nutricionais e bioquímicos, tendo como objetivos específicos analisar:

$\stackrel{1}{4}$ O efeito da suplementação sobre o peso e sobrevida dos animais;

$\stackrel{M}{\longrightarrow}$ O grau da infecção nos órgãos-alvo através de ensaio de recuperação de fungos viáveis;

$\stackrel{\leftrightarrow}{\leftrightarrow}$ O efeito sobre os parâmetros bioquímicos de funções hepáticas, renais, lipídios e proteínas;

$\Leftrightarrow$ A produção de citocinas IL-6, TNF- $\alpha$, IL-10, IL-4 e IFN- $\gamma$ no pulmão, baço e fígado;

$\stackrel{\text { M }}{4}$ O efeito do tratamento sobre a resposta linfoproliferativa de esplenócitos. 
Delineamento experimental $e$

Materiale Métodos 


\section{V - Delineamento do estudo}

Grupos de camundongos foram infectados com a cepa 18 de $P$. brasiliensis (Pb 18) por via intratraqueal, sendo em seguida submetidos à dieta suplementada com $A$. blazei (5 ou $15 \%$ do cogumelo acrescentado à mistura original). A mesma suplementação foi administrada a um segundo grupo de camundongos normais. Diferentes grupos de animais foram sacrificados aos 7 ou 14 dias pós-infecção para avaliação do grau de infecção no pulmão, baço e fígado e do efeito do tratamento sobre a capacidade de resposta imune celular. Por se tratar de um estudo de suplementação dietética, os animais foram também avaliados através de parâmetros que indicassem seu estado nutricional e suas funções hepáticas e renais.

\section{VI - Material e Métodos}

\section{1 - Animais}

Foram utilizados camundongos machos de linhagens BALB/c, com idade entre 45 e 50 dias e peso médio de $20 \mathrm{~g}$, procedentes do Biotério do Laboratório de Pesquisa de Doenças Tropicais do Departamento de Doenças Tropicais, UNESP, Botucatu. Os animais foram mantidos no Biotério do Departamento de Microbiologia e Imunologia do Instituto de Biociências de Botucatu, UNESP, onde foi realizado o estudo, com suprimento de água e ração ad libitum. Todos os procedimentos envolvendo o manuseio dos animais seguiram as recomendações do Colégio Brasileiro de Experimentação Animal (COBEA), após análise e aprovação pela Comissão de Ética em Experimentação Animal (CEEA) do Instituto de Biociências/UNESP (Proc 05/08). 


\section{2 - Cultivo do P. brasiliensis}

A infecção dos animais foi realizada com uso da cepa 18 de $P$. brasiliensis (Pb 18), mantida nos Laboratórios do Departamento de Microbiologia e Imunologia do Instituto de Biociências - UNESP - Botucatu, por subcultivos semanais à $37^{\circ} \mathrm{C}$ no meio de cultura GPY contendo $1,5 \%$ de glicose, $1,0 \%$ de peptona e $0,5 \%$ de extrato de levedura. Para os experimentos de infecção foram obtidas leveduras das colônias com 6 dias de cultivo.

\section{3 - Preparo do inóculo e determinação da viabilidade do $P$.}

\section{brasiliensis}

As células leveduriformes foram colhidas da superfície de meio de cultura com auxílio de alça de platina e transferidas para tubos estéreis contendo pérolas de vidro de $4 \mathrm{~mm}$ de diâmetro e solução salina tamponada estéril (PBS), pH 7,2 e homogeneizadas em agitador de tubos tipo Vortex, por 3 ciclos de 10 segundos. A seguir, a suspensão de leveduras foi incubada à $37^{\circ} \mathrm{C}$ por 5 minutos para sedimentar grumos não desfeitos durante a agitação. O sobrenadante, contendo células isoladas ou com poucos brotamentos foi colhido e alíquotas desta amostra utilizadas para contagem em câmara hemocitométrica tipo Neubauer, utilizando microscópio de contraste de fase. Foram consideradas como células viáveis, aquelas que apresentaram aspecto brilhante (refringente), enquanto as células mortas apresentaram-se com coloração escura. As amostras foram utilizadas somente quando a viabilidade do fungo foi superior a $80 \%$ [79], sendo a concentração de células fúngicas padronizada para $10^{7}$ leveduras viáveis $/ \mathrm{mL}$. 


\section{4 - Infecção e tratamento}

Os animais foram anestesiados por via intraperitoneal (i.p.) com xilazina associado à quetamina, à concentração de $2,5 \%$ em PBS, à dose de $250 \mathrm{mg} / \mathrm{kg}$ de peso corpóreo. Para a inoculação das leveduras de $P$. brasiliensis, os animais anestesiados tiveram suas traquéias expostas, sendo inoculados por via intratraqueal com $100 \mu \mathrm{L}$ de uma suspensão de $10^{7}$ leveduras $/ \mathrm{mL}$ de $\mathrm{Pb} 18\left(10^{6}\right.$ leveduras/animal). Após infecção, os animais foram submetidos à dieta suplementada com 5 ou 15\% de cogumelo (Grupos $\mathrm{Pb} / \mathrm{Ab} 5$ e Pb/Ab 15). O grupo controle de infecção foi constituído de animais infectados e alimentados apenas com a ração comercial (Grupo $\mathrm{Pb}$ ). Animais normais também foram usados para constituição de grupos controle de ração (Ab 5, Ab 15 e Controle). Semanalmente os animais foram acompanhados para registro da sobrevida, peso corpóreo e consumo de água e ração.

\section{5 - Preparo da ração suplementada}

A base da alimentação dos camundongos foi a ração comercial Labina da marca Purina $\AA$, constituída por: proteína bruta $(\min )$ 23,00\%; extrato etéreo ( $\mathrm{min}$ ) 4,00\%; matéria fibrosa $(\max ) 5,00 \%$; matéria mineral $(\max ) 10,00 \%$, cálcio $1,30 \%$ e fósforo (min) $0,85 \%$.

Esta ração foi reidratada, suplementada com 5 ou $15 \%$ de cogumelo $A$. blazei, seco e pulverizado. Entre os nutrientes encontrados no cogumelo incluemse água $(90 \%)$, proteína $(2-40 \%)$, gordura (2-8\%), hidratos de carbono (1-55\%), fibra (3-32\%) e minerais (8-10\%) [80]. 


\section{6 - Recuperação de fungos em órgãos-alvo}

Os animais foram anestesiados e sangrados por punção cardíaca e o sangue depositado em tubos de ensaio para obtenção do soro. Fígado e pulmões dos animais foram removidos e pesados. Um fragmento de cada órgão foi

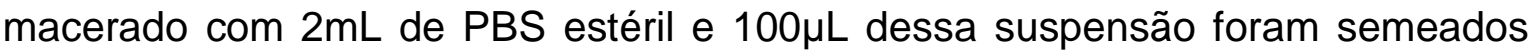
em triplicata em placas de Petri contendo meio de cultura BHI-ágar (BIO-RAD), à $47 \mathrm{~g} / \mathrm{L}$, acrescido de $4 \%$ de soro de cavalo, $50 \mu \mathrm{g} / \mathrm{mL}$ de gentamicina e $5 \%$ de extrato aquoso, preparado a partir de filtrado de cultura de leveduras do fungo cepa 192, cultivadas em meio GPY a $37^{\circ} \mathrm{C}$ sob agitação (120 rpm) por 7 dias [81]. A ocorrência de fungos viáveis nos órgãos-alvo foi demonstrada através da contagem das unidades formadoras de colônia e calculada por grama de peso de cada órgão (UFC/g). O sobrenadante da suspensão foi criopreservado para posterior quantificação de citocinas presentes nos tecidos. O baço foi dividido em 2 fragmentos, sendo um deles processado como descrito acima e o segundo utilizado para análise da atividade linfoproliferativa.

\section{7 - Parâmetros bioquímicos}

O soro obtido por punção cardíaca dos animais foi analisado quanto aos parâmetros bioquímicos de função hepática (AST, ALT e bilirrubinas), renal (uréia e creatinina), lipídios (colesterol e triglicerídeos), glicemia e proteínas. As amostras foram analisadas pelo método de química seca de forma quantitativa utilizando um autoanalisador de multicanais Vitros 950 (Johnson \& Johnson Wayne, PA - USA). Os valores de referência foram baseados no Guia de Referência Veterinária para camundongos fornecido pela Ortho-Clinical Diagnostics - Johnson \& Johnson Company. 


\section{8 - Dosagem de IL-6, TNF- $\alpha$, IL-10, IL-4 e IFN- $\gamma$}

A produção de IL-6, TNF- $\alpha$, IFN- $\gamma$, IL-10 e IL-4 nos órgãos alvo foi determinadas pela reação de ELISA, em homogenatos de pulmão, baço e fígado.

As placas de 96 alvéolos de fundo plano (Maxsorb-Nunc Life Tech Inc., $\mathrm{MD}, \mathrm{USA}$ ) foram sensibilizadas por $18 \mathrm{~h}$ à $5^{\circ} \mathrm{C}$ com anticorpo monoclonal de camundongo específico para a citocina de interesse (R\&D Systems), diluído em PBS, pH 7.2, à concentração de $2 \mu \mathrm{g} / \mathrm{mL}$ (IL6 e IL10), $0.8 \mu \mathrm{g} / \mathrm{mL}$ (TNF- $\alpha$ ) ou 0,5 $\mu \mathrm{g} / \mathrm{mL}$ (IL4 e IFN- $\gamma$ ). Após esse período, os alvéolos foram lavados 3 vezes com 300 $\mu \mathrm{L}$ de PBS pH 7.2, com Tween 20 a 0,05\% (PBST). O bloqueio da placa foi realizado com PBS contendo $5 \%$ de sacarose, $0,5 \%$ de Tween $20,1 \%$ de soro albumina bovina (BSA) ou $10 \%$ de soro bovino fetal (SBF) e $0,005 \%$ de $\mathrm{NaN}_{3}$ (azida sódica) e incubada à temperatura ambiente, por 2 horas. A seguir, a placa foi lavada e foram adicionados $100 \mu \mathrm{L}$ da citocina em diluição seriada para obtenção da curva padrão. Nos alvéolos restantes foram colocados $100 \mu \mathrm{L}$ dos sobrenadantes gerados conforme descrito no item 5 .

Após 2 horas de incubação à temperatura ambiente, as placas foram lavadas e adicionado o anticorpo policlonal biotinilado de cabra contra a citocina de interesse (R\&D Systems), à concentração de $200 \mathrm{ng} / \mathrm{mL}$ (IL6), $400 \mathrm{ng} / \mathrm{mL}$ (IL10), $150 \mathrm{ng} / \mathrm{mL}$ (TNF $\alpha$ ) e 0,5 $\mu \mathrm{g} / \mathrm{mL}$ (IL4 e IFN- $\gamma$ ), seguindo-se incubação por 2 horas à temperatura ambiente. A placa foi lavada novamente com PBST e adicionados $100 \mu \mathrm{L}$ de avidina conjugada com peroxidase (Sigma) diluída à 1:10.000 em PBS contendo $0,1 \%$ de BSA por 30 minutos à $37^{\circ} \mathrm{C}$. Em seguida, adicionou-se $100 \mu \mathrm{L}$ do substrato enzimático, constituído por $12,5 \mathrm{~mL}$ de tampão citrato-fosfato $0,1 \mathrm{M}$, pH 5.0 contendo $10 \mu \mathrm{L}$ de $\mathrm{H}_{2} \mathrm{O}_{2}$ a $30 \%$ (Sigma) e $1 \mathrm{mg} / \mathrm{mL}$ de 
ortofenilenodiamina (Sigma). As placas foram incubadas à temperatura ambiente por 15 minutos, a reação foi bloqueada pela adição de $50 \mu \mathrm{L}$ de ácido sulfúrico $2 \mathrm{M}$

e a leitura da placa realizada em leitor de ELISA (Multiskan EFLSB, Helsinki, Finland) em comprimento de onda de 492nm. Os níveis de citocinas nos homogenatos de cultura foram calculados e expressos em $\mathrm{pg} / \mathrm{g}$ de tecido do órgão analisado.

\section{9 - Atividade linfoproliferativa}

Para avaliar o efeito do tratamento sobre a resposta celular ao agente infeccioso, esplenócitos foram cultivados em presença de gp43 de $\mathrm{Pb}$, antígeno imunodominante do fungo [82] ou Concanavalina A (Con A) Sigma, de acordo com Baida et al. [45]. Brevemente, um fragmento de baço foi macerado em meio de cultura RPMI 1640, suplementado com 10\% de soro bovino fetal, gentamicina (40g/L), L-glutamina (25mM) e HEPES (22,5g/L) (meio completo). A suspensão de células totais foi lavada por centrifugação e após avaliação de viabilidade celular, a concentração de células foi ajustada para $4 \times 10^{6}$ células $/ \mathrm{mL}$. As células foram distribuídas em placas de microcultura de 96 escavações de fundo plano $(100 \mu \mathrm{L})$ e cultivadas por 5 dias em presença de $10 \mu \mathrm{g} / \mathrm{mL}$ de gp43 ou por 3 dias em presença de $3,5 \mu \mathrm{g} / \mathrm{mL}$ de Con A. Cerca de 24 horas antes do término da cultura, foram adicionados às culturas $30 \mu \mathrm{L}$ de MTT $(5 \mathrm{mg} / \mathrm{mL}) \quad(3-(4,5-$ dimethylthiazolyl)-2,5-diphenyl-tetrazolium bromide, Sigma) para marcação das células viáveis. Após 2 horas adicionais, os sobrenadantes foram retirados e as células solubilizadas com dimetilsulfóxido (DMSO). A determinação da densidade óptica resultante da incorporação de MTT foi feita em espectrofotômetro com filtro de $540 \mathrm{~nm}$. 
O índice de estimulação foi calculado de acordo com a fórmula:

$\mathrm{IE}=$ D.O. culturas estimuladas

D.O. culturas controles

\section{0 - Análise Estatística}

Os dados foram submetidos à análise de variância - ANOVA e as análises de comparações múltiplas foram feitas pelo teste de Tukey. Os procedimentos estatísticos foram aplicados empregando-se o programa GraphPad Instat 3.05, GraphPad Software, San Diego, CA USA. Foram considerados significantes os dados cujas diferenças apresentaram probabilidade de erro inferior a $5 \%(p<0,05)$. 
Resultados 


\section{VII - Resultados}

\section{1 - Peso corpóreo e consumo de ração}

A avaliação do peso dos animais não-infectados mostra que o ganho de peso foi similar nos 3 grupos $(2,78 \mathrm{~g} \pm 0,34$ no Controle normal, $3,195 \mathrm{~g} \pm 0,50$ no grupo $A b 5$ e 2,916 $\pm 0,18$ no grupo Ab 15), não se observando influência da suplementação dietética sobre esse parâmetro (Fig 1). Entre os animais infectados observou-se que todos os grupos apresentaram redução de peso corpóreo mediano no início da infecção, em relação ao Controle normal (Pb: 2,188 $\pm 1,48<; \mathrm{Pb} / \mathrm{Ab} 5: 1,07 \pm 1,25<\mathrm{e} \mathrm{Pb} / \mathrm{Ab}$ 15: $2,43 \pm 1,66<)$. Após 2 semanas houve recuperação do peso todos esses animais $(\mathrm{Pb} 2,99 \pm 1,09, \mathrm{~Pb} / \mathrm{Ab} 53,33 \pm$ $1,01$ e $\mathrm{Pb} / \mathrm{Ab} 152,59 \pm 1,99)$. Camundongos infectados tratados com ração suplementada com $15 \%$ de $A$. blazei apresentaram redução do peso corpóreo mais acentuada que os demais grupos $(2,43 g \pm 1,66)$, bem como menor nível de recuperação em relação ao peso inicial $(2,59 \mathrm{~g} \pm 1,99)$.

O consumo médio diário de ração entre os animais não infectados foi de $17,65 \pm 0,89 \mathrm{~g} / \mathrm{dia}$ (Controle), 15,41 $\pm 0,95 \mathrm{~g} / \mathrm{dia}(\mathrm{Ab} 5)$ e 17,73 \pm 0,56 g/dia (Ab 15). Entre os animais infectados o grupo $\mathrm{Pb} / \mathrm{Ab} 5$ foi o que mostrou maior média de consumo com 16,78 $\pm 0,83 \mathrm{~g} /$ dia, enquanto os demais tiveram consumo médio de $14,79 \pm 0,92 \mathrm{~g} / \mathrm{dia}(\mathrm{Pb})$ e $14,12 \pm 0,44 \mathrm{~g} / \mathrm{dia}(\mathrm{Pb} / \mathrm{Ab} 15)$. De modo geral o consumo total de ração entre os animais infectados foi ligeiramente inferior ao dos animais não infectados (Fig 2). 


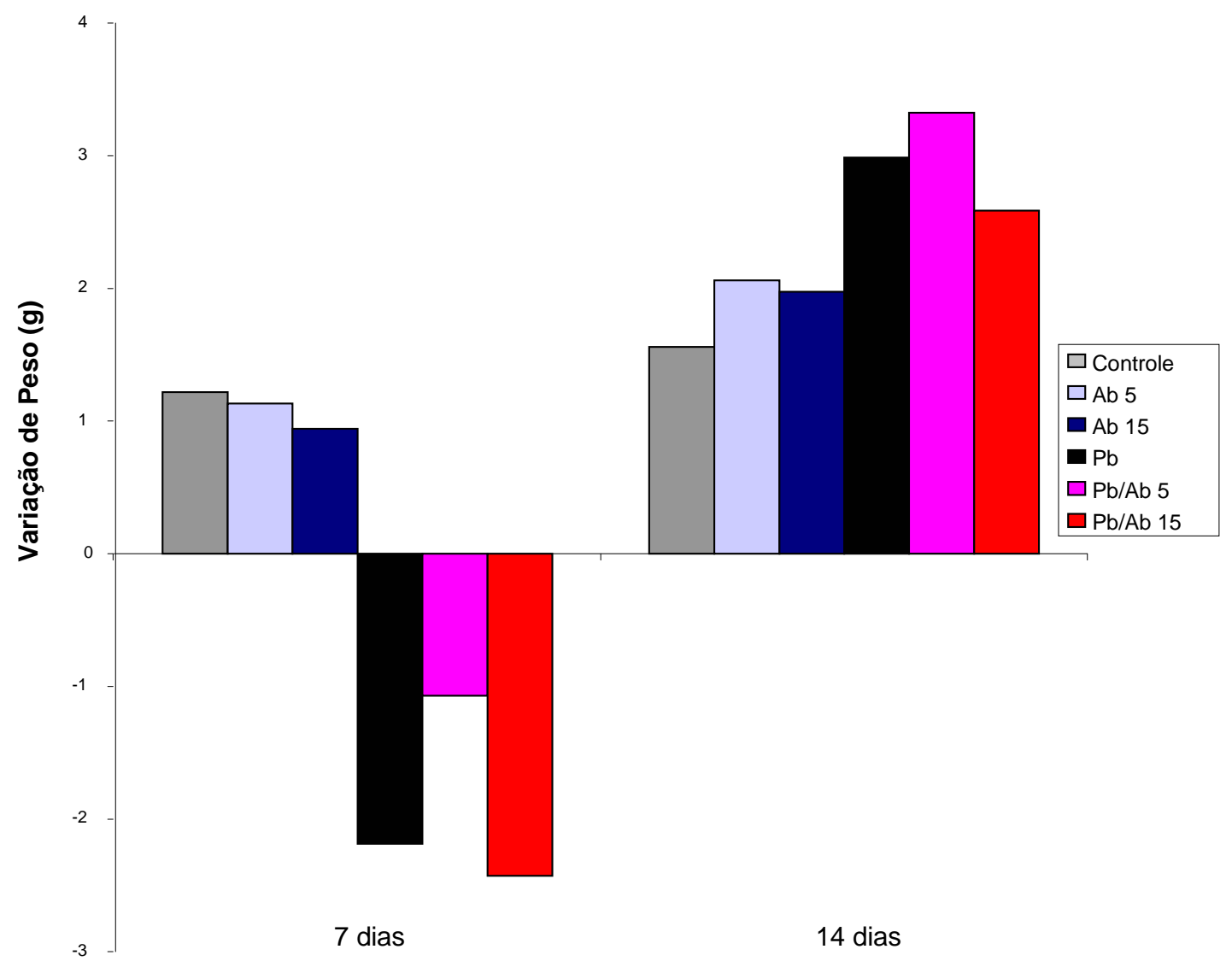

Figura 1 - Variação de peso $(\mathrm{g})$ de camundongos normais ou infectados com $P$. brasiliensis, tratados com ração convencional (Controle e $\mathrm{Pb}$ ) ou suplementada com cogumelo $A$. blazei à $5 \%(A b 5$ e $\mathrm{Pb} / \mathrm{Ab} 5)$ ou $15 \%$ (Ab 15 e $\mathrm{Pb} / \mathrm{Ab}$ 15). Registros obtidos nos dias 0 (peso de referência), 7 e $14(n=10)$. Resultados expressos em mediana. 


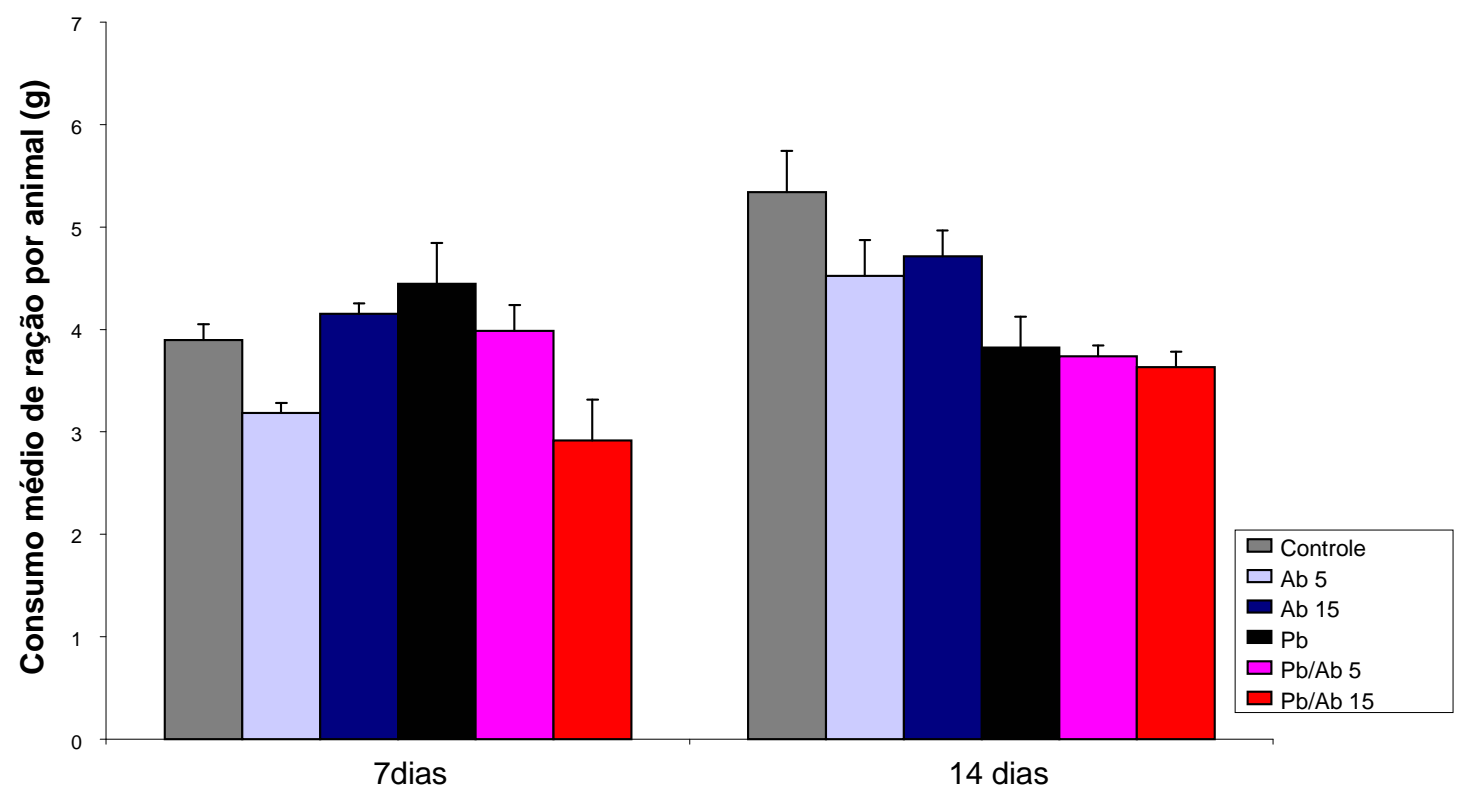

Figura 2 - Consumo médio de ração $(\mathrm{g})$ de camundongos normais ou infectados com $P$. brasiliensis, tratados com ração convencional (Controle e $\mathrm{Pb}$ ) ou suplementada com cogumelo $A$. blazei à $5 \%$ (Ab 5 e $\mathrm{Pb} / \mathrm{Ab} 5$ ) ou $15 \%$ (Ab 15 e Pb/Ab 15). As avaliações foram realizadas após 7 e 14 dias de infecção $(n=8)$. Resultados expressos em média \pm erro padrão. 
2- Efeito do A. blazei sobre a sobrevida dos animais infectados e recuperação de fungos viáveis de órgãos alvo

A introdução de $A$. blazei na dieta dos animais infectados parece ser prejudicial ao hospedeiro, visto que, embora a sobrevida dos animais nos 3 grupos não mostre diferenças significantes, os únicos animais que foram a óbito pertenciam aos grupos que consumiram ração suplementada com 5\% (1 óbito entre 10 animais) ou 15\% (2/10 óbitos) do cogumelo.

Essa observação foi reforçada pelo ensaio de recuperação de fungos viáveis do pulmão (Fig 3), visto que no controle de infecção foram recuperadas 391,25 \pm 221.85 UFCs de $P$. brasiliensis, observou-se média de 876,13 \pm 406,60 UFCs nos animais do grupo Pb/Abl 5 e 4185,33 \pm 692,90 colônias nos animais do grupo $\mathrm{Pb} / \mathrm{Abl}$ 15, aos 7 dias de infecção. Na segunda semana de infecção, houve um aumento de aproximadamente $84 \%$ na recuperação de fungos viáveis do pulmão de animais controle, em comparação com a primeira semana $(719,00 \pm$ 301,00 UFCs). No entanto, ao contrário do detectado no período de 7 dias, a suplementação nutricional com $A$. blazei promoveu intensa redução no número de fungos viáveis $(34,33 \pm 18,49$ UFCs no grupo Pb/Ab5 e 336,00 $\pm 198,68$ UFCs no grupo $\mathrm{Pb} / \mathrm{Ab} 15)$. 


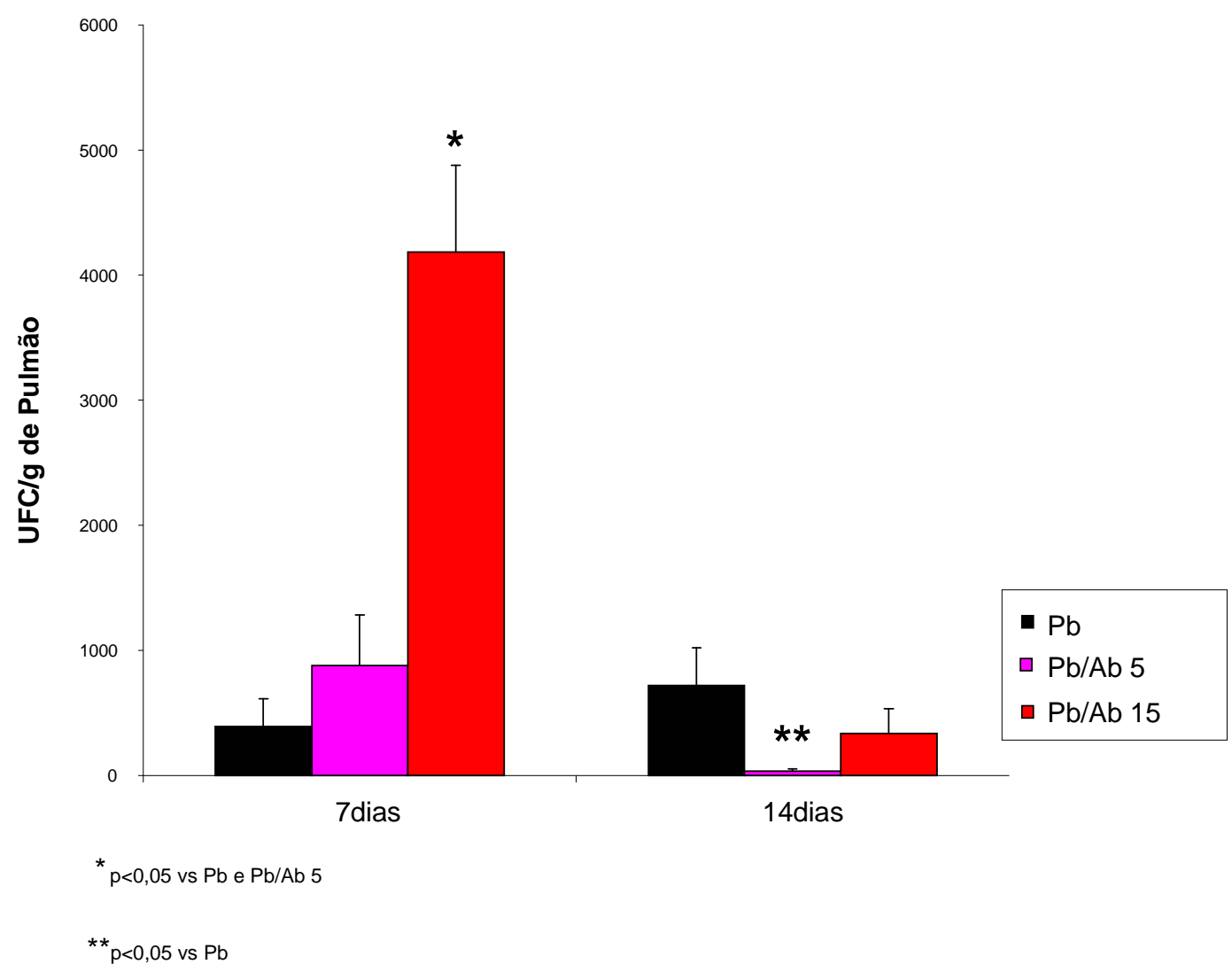

Figura 3 - Número de leveduras viáveis (UFC) recuperadas a partir de tecido pulmonar 7 e 14 dias após a infecção com 106 células leveduriformes $(\mathrm{Pb})$ e tratamento com ração suplementada com $5 \%$ (Pb/Ab 5) ou $15 \%$ (Pb/Ab 15) de $A$. blazei. Um fragmento de tecido pulmonar dos animais infectados foi macerado em PBS e semeado em triplicata em meio BHI-ágar. O desenvolvimento de colônias foi avaliado após 10 dias de cultivo. Dados são expressos como média \pm erro padrão $(n=8) .(p<0,05)$ 


\section{3- Parâmetros bioquímicos}

As concentrações séricas de proteínas totais foram significativamente maiores no grupo $\mathrm{Pb} / \mathrm{Ab} 5$ aos 7 dias de tratamento, em comparação com o grupo Controle, retornando aos níveis regulares aos 14 dias (Fig 4). Entretanto, não se observou influência isolada da dieta sobre a concentração de proteínas totais do soro no período avaliado, visto que os grupos $A b 5$ e $A b 15$ não sofreram alteração desse parâmetro.

Em relação aos níveis de glicose não se observaram diferenças entre os grupos, mas os dados estatísticos indicam tendência à redução nos animais infectados tratados com a ração suplementada $(\mathrm{Pb} / \mathrm{Ab} 5 \mathrm{e} \mathrm{Pb} / \mathrm{Ab}$ 15) no período mais precoce da avaliação, com recuperação na segunda semana (Fig 5).

A análise de metabólitos relacionados à função hepática mostra que durante a fase aguda da infecção, há aumento dos níveis de bilirrubinas ( $\mathrm{Pb}-$ 2,0mg/dL) com aumento significativo nos animais alimentados com a dieta suplementada ( $\mathrm{Pb} / \mathrm{Ab} 5$ - 4,52mg/dL e Pb/Ab 15 - 4,22mg/dL; $\mathrm{p}<0,05$;Fig $6 \mathrm{~A}$ ). Esses níveis retornaram à faixa de normalidade aos 14 dias de infecção. Não se observou efeito isolado da suplementação.

Os níveis de AST nos animais normais mostraram-se superiores aos valores de referência (Fig. 6B), nos dois períodos de avaliação. Animais que receberam $15 \%$ de $A$. blazei na dieta, mantiveram os níveis de AST mais elevados que os valores de referência, ao passo que a suplementação com $5 \%$ mostra tendência a normalização desse parâmetro. Não se observou alteração significante nos níveis séricos de ALT (Fig 6C). 
Os parâmetros bioquímicos de funções renais indicaram que a infecção, associada à suplementação com $15 \%$ de $A$. blazei aumentou os níveis de uréia na primeira semana $(p<0,05)$, sem influenciar a produção de creatinina (Fig 7). 0 processo infeccioso elevou discretamente os níveis de colesterol total, sem efeito relevante nos níveis de triglicerídeos (Fig.8). 


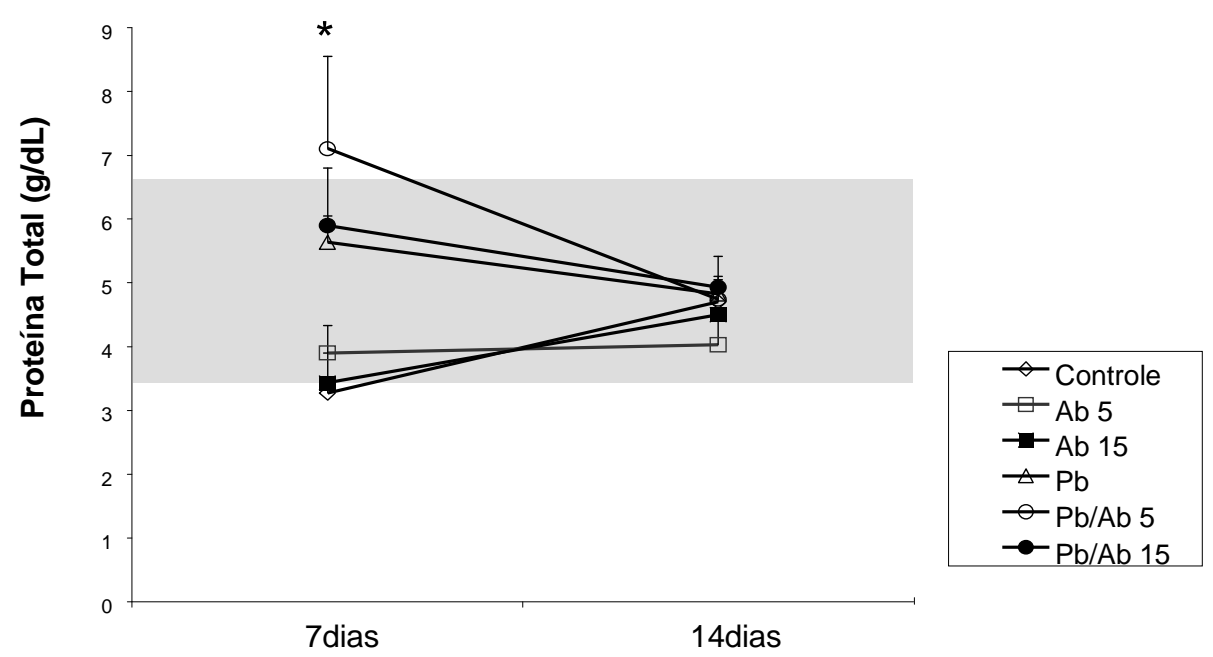

Figura 4 - Níveis séricos de proteínas totais $(\mathrm{g} / \mathrm{dL})$ de camundongos normais ou infectados com $P$. brasiliensis, tratados com ração convencional (Controle e $\mathrm{Pb}$ ) ou suplementada com cogumelo $A$. blazei à $5 \%$ ( $\mathrm{Ab} 5$ e $\mathrm{Pb} / \mathrm{Ab} 5$ ) ou 15\% (Ab 15 e $\mathrm{Pb} / \mathrm{Ab}$ 15). As avaliações foram realizadas após 7 e 14 dias da infecção pelo método quantitativo de química seca utilizando autoanalisador de multicanais Vitros 950 (Johnson \& Johnson - Wayne, PA - USA) ( $n=8)$. Resultados expressos em média \pm erro padrão.

* $\mathrm{p}<0,05$ versus Controle

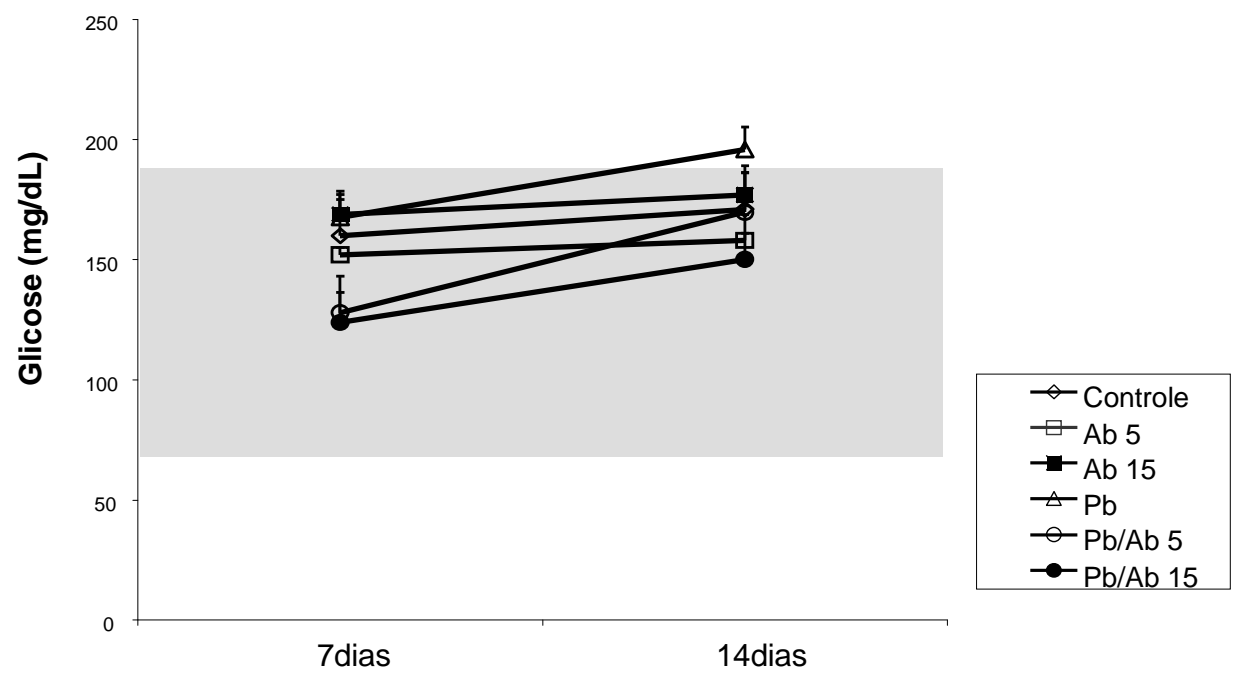

Figura 5 - Níveis séricos de glicose $(\mathrm{mg} / \mathrm{dL})$ de camundongos normais ou infectados com $P$. brasiliensis, tratados com ração convencional (Controle e $\mathrm{Pb}$ ) ou suplementada com cogumelo $A$. blazei à $5 \%$ ( $\mathrm{Ab} 5 \mathrm{e}$ $\mathrm{Pb} / \mathrm{Ab} 5$ ) ou $15 \%$ (Ab $15 \mathrm{e} \mathrm{Pb/Ab} \mathrm{15).} \mathrm{As} \mathrm{avaliações} \mathrm{foram} \mathrm{realizadas} \mathrm{após} 7$ e 14 dias da infecção pelo método quantitativo de química seca utilizando autoanalisador de multicanais Vitros 950 (Johnson \& Johnson - Wavne. PA - USA) ( $n=8)$. Resultados expressos em média \pm erro padrão. 

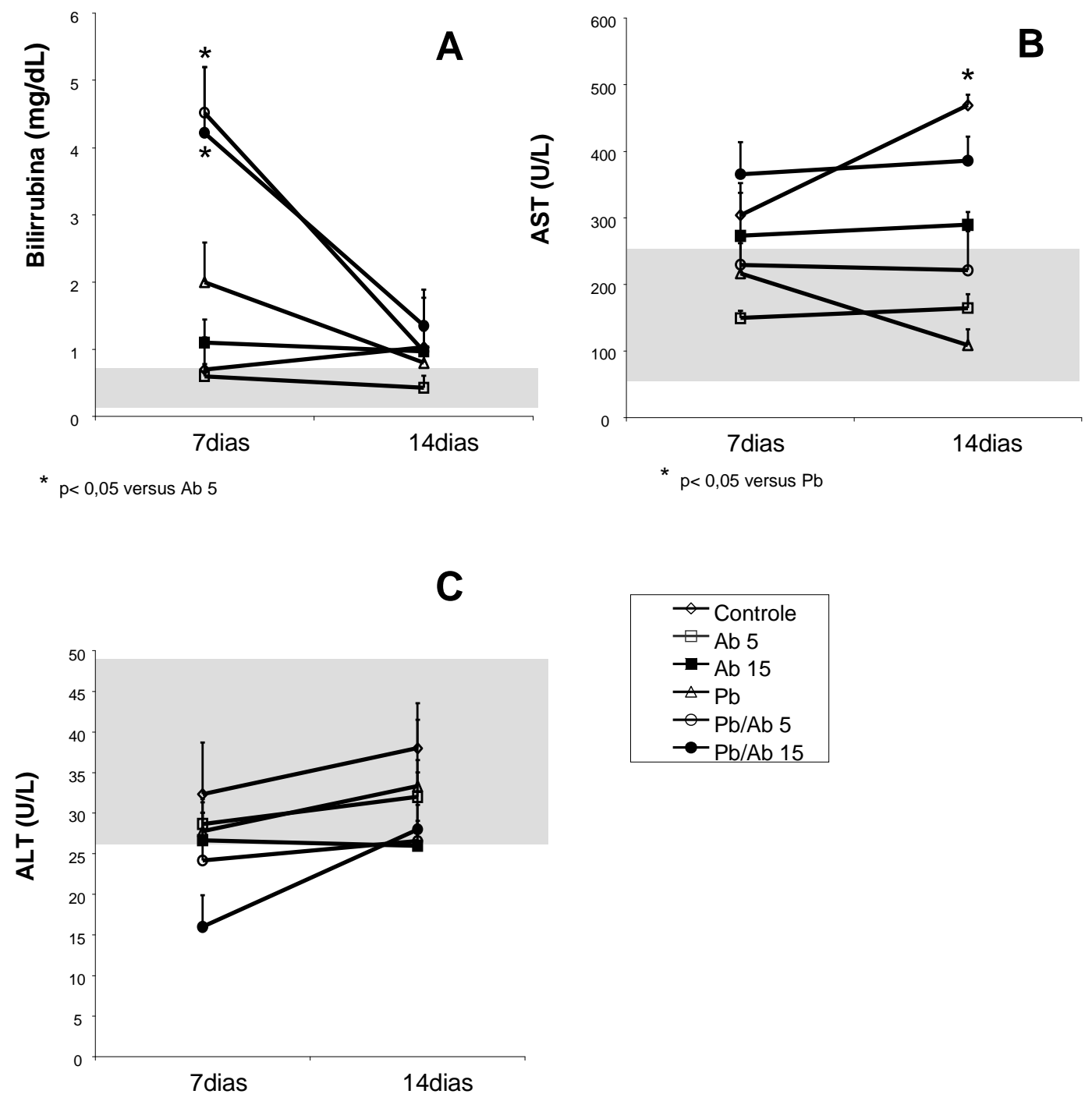

Figura 6 - (A) Níveis séricos de bilirrubinas (mg/dL), (B) AST (U/L)e (C) ALT (U/L) de camundongos normais ou infectados com $P$. brasiliensis, tratados com ração convencional (Controle e $\mathrm{Pb}$ ) ou suplementada com cogumelo $A$. blazei à $5 \%$ ( $\mathrm{Ab} 5$ e $\mathrm{Pb} / \mathrm{Ab} 5$ ) ou $15 \%$ (Ab 15 e Pb/Ab 15). As avaliações foram realizadas após 7 e 14 dias da infecção pelo método quantitativo de química seca utilizando autoanalisador de multicanais Vitros 950 (Johnson \& Johnson - Wayne, PA - USA) ( $n=8)$. Resultados expressos em média \pm erro padrão. 


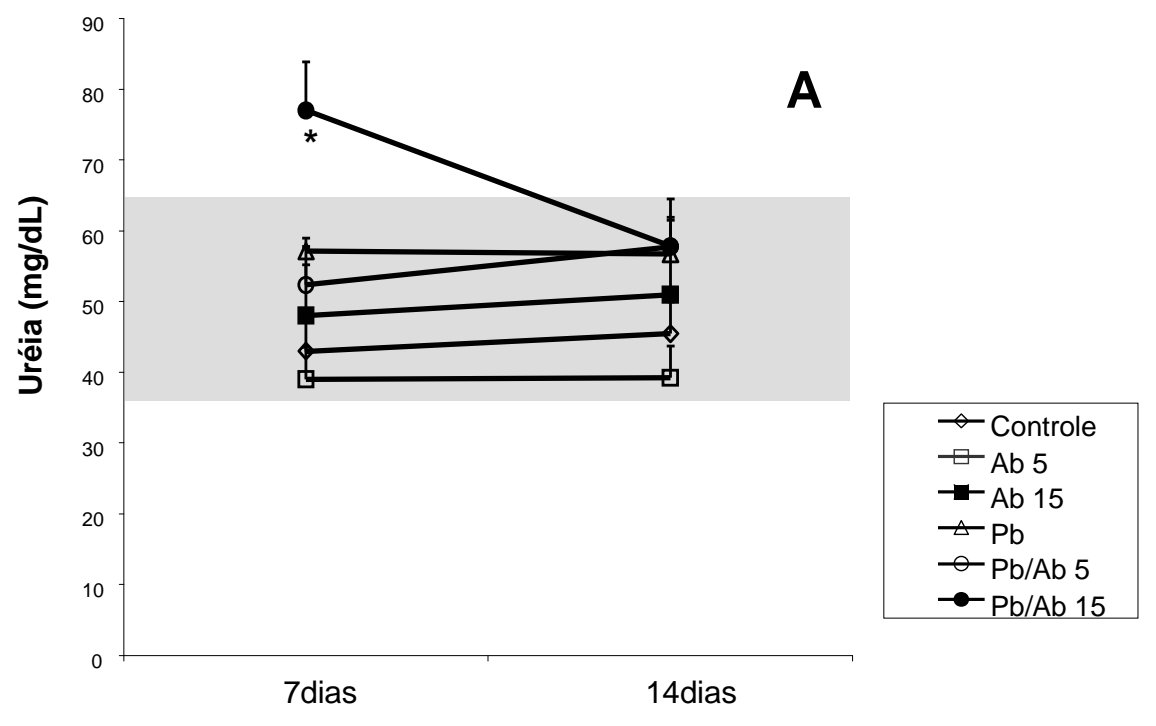

$* \mathrm{p}<0.05 \mathrm{vs} \mathrm{Pb} / \mathrm{Ab} 5$

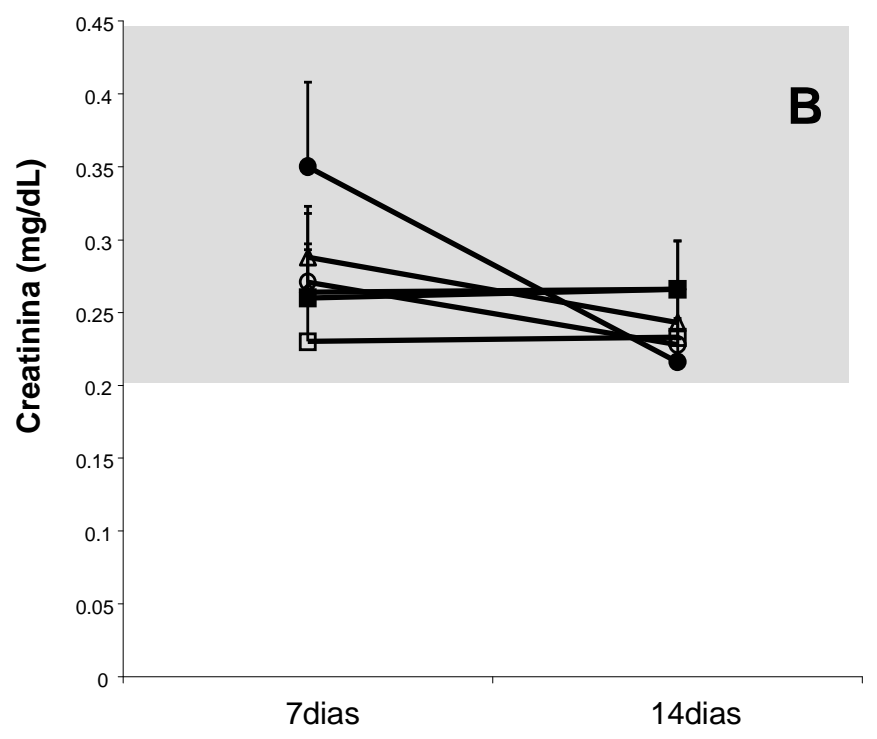

Figura 7 - (A) Níveis séricos de uréia $(\mathrm{mg} / \mathrm{dL})$ e (B) creatinina $(\mathrm{mg} / \mathrm{dL})$ de camundongos normais ou infectados com $P$. brasiliensis, tratados com ração convencional (Controle e $\mathrm{Pb}$ ) ou suplementada com cogumelo A. blazei à $5 \%$ (Ab 5 e Pb/Ab 5) ou 15\% (Ab 15 e Pb/Ab 15). As avaliações foram realizadas após 7 e 14 dias da infecção pelo método quantitativo de química seca utilizando autoanalisador de multicanais Vitros 950 (Johnson \& Johnson - Wayne, PA - USA) $(n=8)$. Resultados expressos em média \pm erro padrão. 

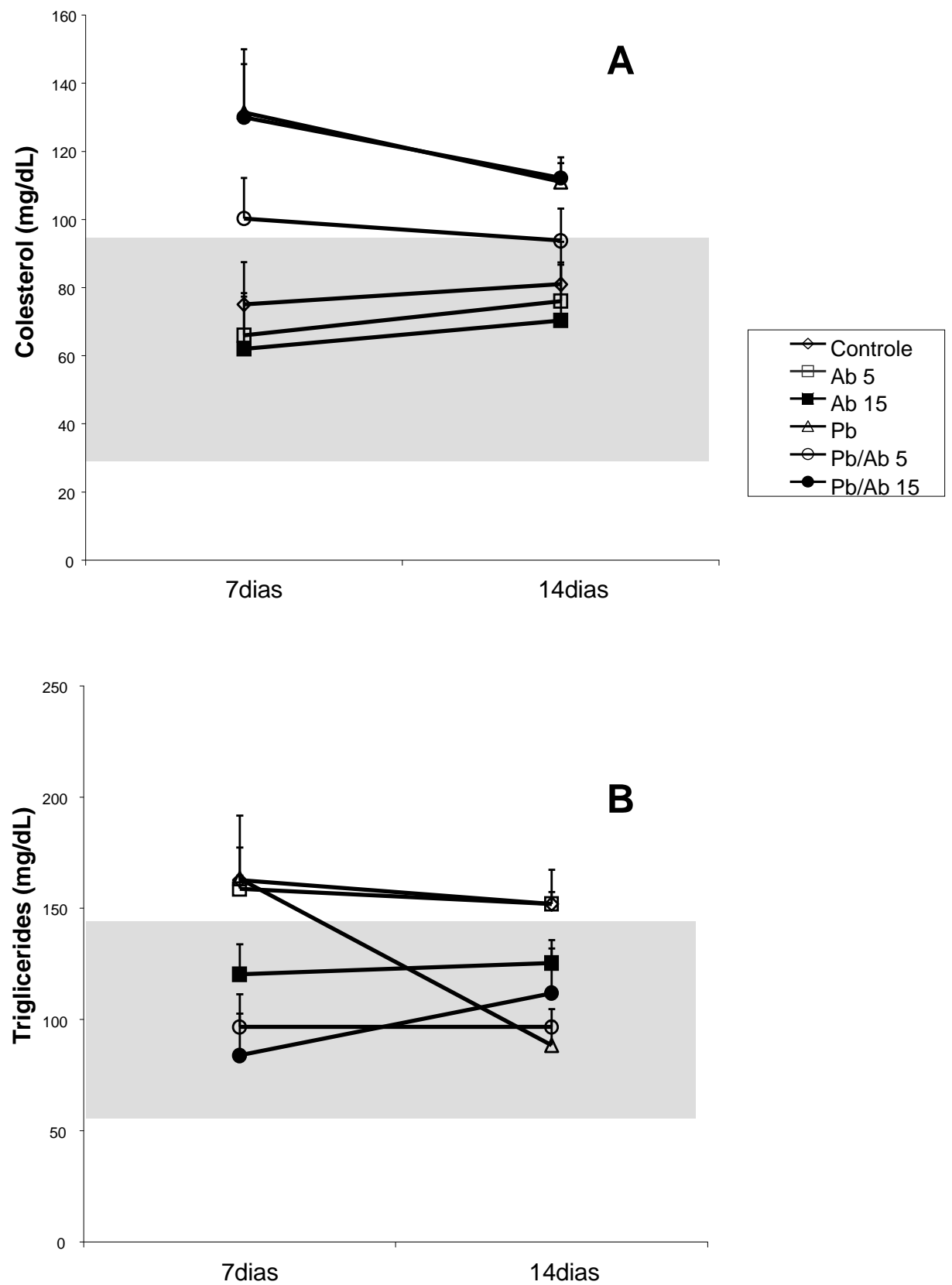

Figura 8 - (A) Níveis séricos de colesterol $(\mathrm{mg} / \mathrm{dL})$ e (B) triglicerides $(\mathrm{mg} / \mathrm{dL})$ de camundongos normais ou infectados com $P$. brasiliensis, tratados com ração convencional (Controle e $\mathrm{Pb}$ ) ou suplementada com cogumelo $A$. blazei à $5 \%$ (Ab 5 e $\mathrm{Pb} / \mathrm{Ab} 5$ ) ou $15 \%$ (Ab 15 e $\mathrm{Pb} / \mathrm{Ab} 15)$. As avaliações foram realizadas após 7 e 14 dias da infecção pelo método quantitativo de química seca utilizando autoanalisador de multicanais Vitros 950 (Johnson \& Johnson - Wayne, PA - USA) $(n=8)$. Resultados expressos em média \pm erro padrão. 


\section{4 - Atividade Linfoproliferativa}

Com o objetivo de avaliar o efeito da suplementação dietética sobre o potencial de resposta imune do hospedeiro, avaliamos a atividade linfoproliferativa de esplenócitos frente ao antígeno de Pb189 (gp43) e ao mitógeno para linfócitos $\mathrm{T}(\operatorname{Con} \mathrm{A})$.

Em relação à resposta específica nenhum dos grupos respondeu antígeno glicoprotéico gp43 (dados não mostrados). O ensaio realizado aos 7 dias com o mitógeno, por sua vez, demonstrou que a infecção pelo Pb18 induziu intensa redução da atividade proliferativa celular, observando-se que os animais normais apresentaram índice de estimulação da ordem de 0,668 $\pm 0,045$, enquanto 0 controle da infecção apresentou índice de proliferação médio de 0,205 \pm 0,004 (Fig 9). Aos 14 dias de infecção, observamos recuperação da atividade linfoproliferativa dos esplenócitos de animais infectados, especialmente daqueles que receberam ração suplementada com o cogumelo. 


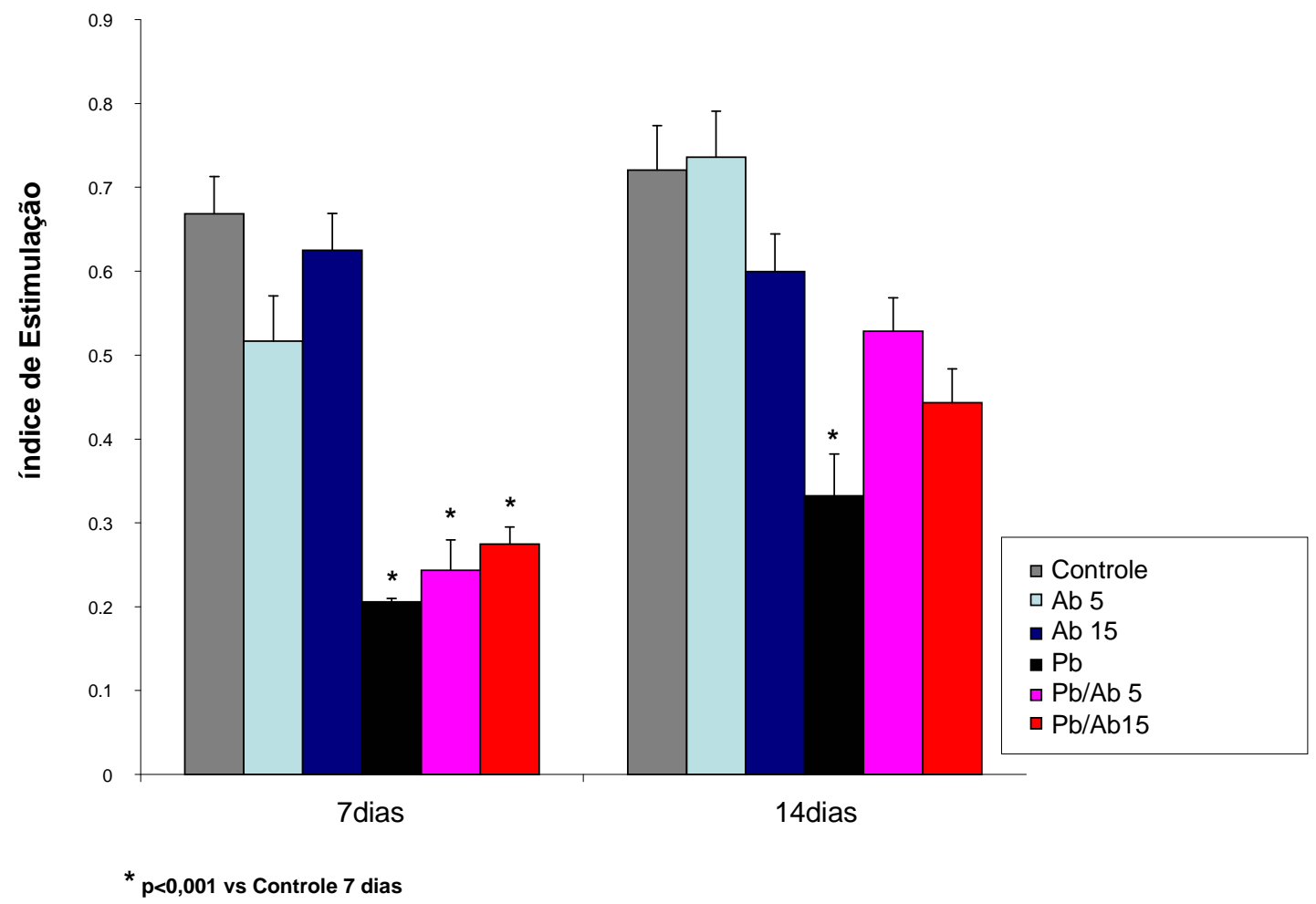

Figura 9 - Atividade linfoproliferativa de esplenócitos de camundongos BALB/C normais ou infectados com $P$. brasiliensis, tratados com ração convencional (Controle e $\mathrm{Pb} 18$ ) ou suplementada com cogumelo A. blazei à $5 \%(\mathrm{Ab} 5$ e $\mathrm{Pb} / \mathrm{Ab} 5)$ ou $15 \%$ (Ab 15 e $\mathrm{Pb} / \mathrm{Ab} 15)$. As avaliações foram realizadas após 7 e 14 dias da infecção. Esplenócitos à concentração de $4 \times 106 \mathrm{cel} / \mathrm{mL}$ foram distribuídos em microplacas de cultivo celular e incubadas por $72 \mathrm{~h}$ à $37^{\circ} \mathrm{C}$ em estufa de $\mathrm{CO} 25 \%$ em presença de ConA. O índice de estimulação foi calculado com base na incorporação de MTT, medido por espectrofotometria em comprimento e onda de $540 \mathrm{~nm}(\mathrm{n}=8)$. Resultados expressos em média \pm erro padrão. 


\section{5 - Efeito da infecção e tratamento dietético sobre o perfil de citocinas} do pulmão

Visto que o pulmão foi o órgão alvo afetado pela infecção experimental e que apresentou leveduras viáveis até 14 dias após a infecção, investigamos o perfil de citocinas associado à infecção e aos tratamentos dietéticos empregados. Assim, na figura 10(A - E) podemos observar que a infecção determinou tendência de aumento nos níveis de TNFa aos 7 dias de infecção $(0,05<p<0,1$; Fig. 10B), enquanto a suplementação dos animais infectados induziu níveis significantemente elevados de TNF- $\alpha$ aos 14 dias ( $p<0,05$ no grupo $\mathrm{Pb} / \mathrm{Ab} 15)$. Em contraste com esses achados, essa ração induziu redução da capacidade de produção de IL-10 ( $p<0,01$; Fig. 10D). Na realidade, os resultados indicam que o cogumelo reduz a geração de IL10 nos pulmões tanto em animais infectados quanto em animais normais na primeira semana. $O$ tratamento dos animais infectados com rações suplementadas mostram também uma tendência de aumento dos níveis de INF- $\gamma(0,05<p<0,1)$. Entretanto o efeito sobre a produção de IL4, não é conclusivo, com tendência a redução apenas nos animais tratados com ração suplementada à 5\% (Fig 10E) 

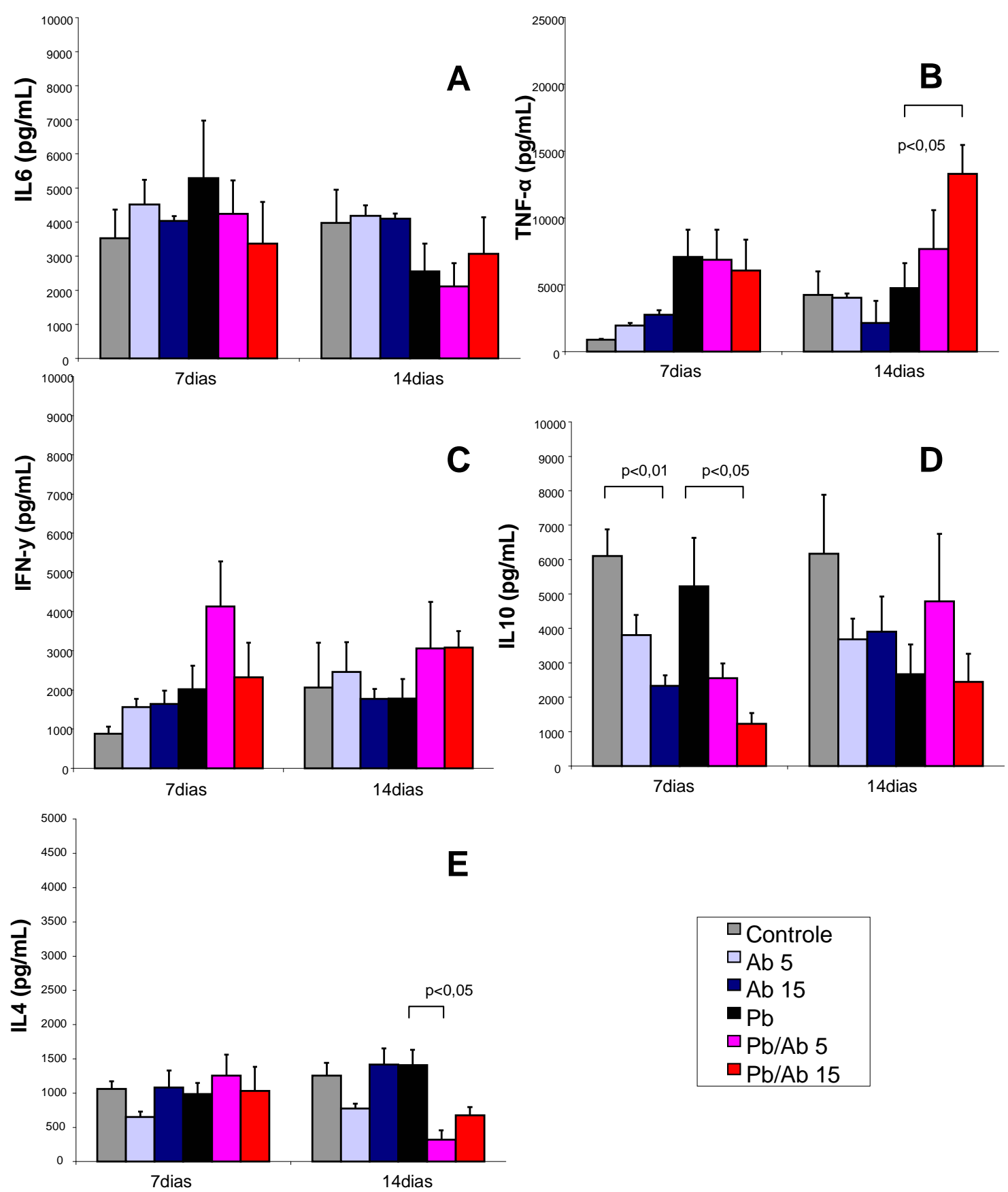

$\square$ Controle

$\square \mathrm{Ab} 5$

- Ab 15

- $\mathrm{Pb}$

$\square \mathrm{Pb} / \mathrm{Ab} 5$

$\square \mathrm{Pb} / \mathrm{Ab} 15$

Figura 10 - Determinação de IL-6 (A), TNFa (B), IFN-ץ (C), IL10 (D) e IL4 (E) nos sobrenadantes do pulmão de camundongos normais ou infectados com $P$. brasiliensis, tratados com ração convencional (Controle e $\mathrm{Pb}$ ) ou suplementada com cogumelo $A$. blazei à $5 \%(\mathrm{Ab} 5 \mathrm{e} \mathrm{Pb} / \mathrm{Ab} 5)$ ou $15 \%$ (Ab 15 e $\mathrm{Pb} / \mathrm{Ab}$ 15). As avaliações foram realizadas após 7 e 14 dias de infecção pelo método de ELISA. Dados são expressos com média \pm erro padrão $(n=8)$. 


\section{7 - Efeito da infecção e tratamento dietético sobre o perfil de citocinas} do baço e fígado

Embora não tenham sido isolados fungos viáveis do baço e fígado de nenhum dos animais estudados, esses órgãos são importantes alvos da disseminação hematogênica do $P$. brasiliensis. Além disso, o baço é um dos órgãos linfóides secundários de fundamental importância para o estabelecimento da resposta imune adaptativa, concentrando parcela considerável das células imunocompetentes. Assim, esses dois órgãos também foram avaliados em relação à síntese in situ de citocinas.

O processo infeccioso induziu elevação da produção de IFN- $\gamma$ no baço na primeira semana de infecção e a administração de ração suplementada exacerbou esse efeito tanto aos 7 quanto aos 14 dias (Fig 11C e 11B). A suplementação também induziu tendência de aumento da produção de TNF- $\alpha$ nos animais infectados, enquanto a administração de $15 \%$ de $A$. blazei aos animais normais reduziu significantemente a produção dessa citocina.

Diferentemente do que se observou no pulmão em que houve redução da produção de IL-10 em decorrência do tratamento, observamos que no baço, a infecção promoveu aumento na produção dessa citocina aos 7 dias de infecção. Aos 14 dias, observa-se normalização dos níveis de IL-10 no grupo Pb, enquanto os animais infectados tratados com $A$. blazei continuaram com níveis mais elevados. Não observamos efeito significante do tratamento nem da infecção sobre a produção de IL-4 nesse órgão (Fig 12E).

No fígado, observamos que a infecção induziu redução dos níveis de TNF$\alpha$ (Fig 12B). Observamos que a administração do cogumelo aos animais 
infectados $(\mathrm{Pb} / \mathrm{Ab5}$ e $\mathrm{Pb} / \mathrm{Ab} 15)$ induz aumento significante de IL-6 e IFN- $\gamma$, especialmente aos 14 dias de infecção (Fig 12A e 12C). A produção de IL-10 foi ligeiramente reduzida pela infecção mas a administração de cogumelo a 15\% aumentou significantemente sua produção no grupo $A b 15$ aos 7 dias e no grupo $\mathrm{Pb} / \mathrm{Ab} 15$ aos 14 dias. 

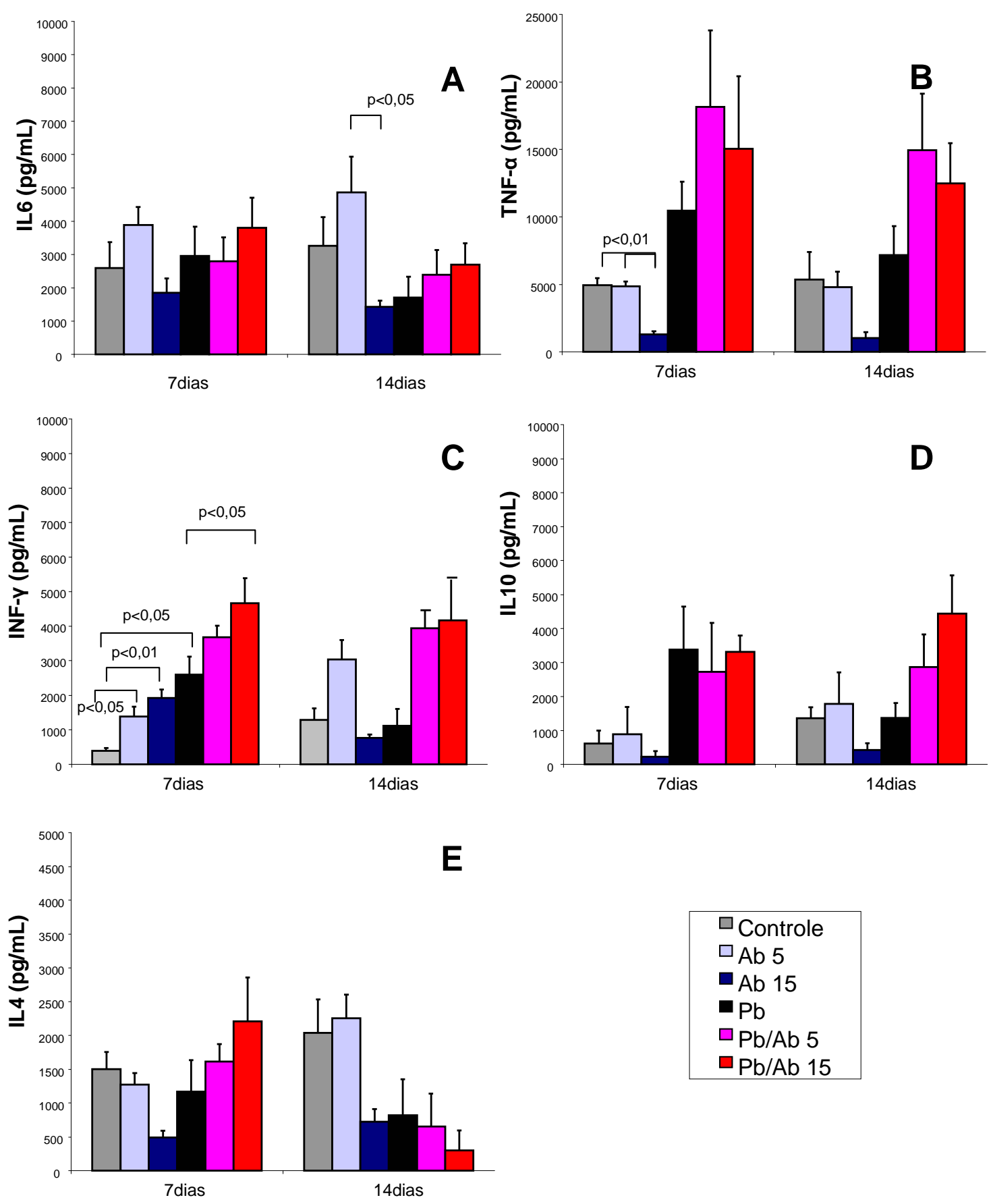

Figura 11 - Determinação de IL-6 (A), TNFa (B), IFN-y (C), IL10 (D) e IL4 (E) nos sobrenadantes do baço de camundongos normais ou infectados com $P$. brasiliensis, tratados com ração convencional (Controle e $\mathrm{Pb}$ ) ou suplementada com cogumelo $A$. blazei à $5 \%(\mathrm{Ab} 5 \mathrm{e} \mathrm{Pb} / \mathrm{Ab} 5)$ ou $15 \%$ (Ab 15 e $\mathrm{Pb} / \mathrm{Ab} 15)$. As avaliações foram realizadas após 7 e 14 dias de infecção pelo método de ELISA. Dados são expressos com média \pm erro padrão $(n=8)$. 

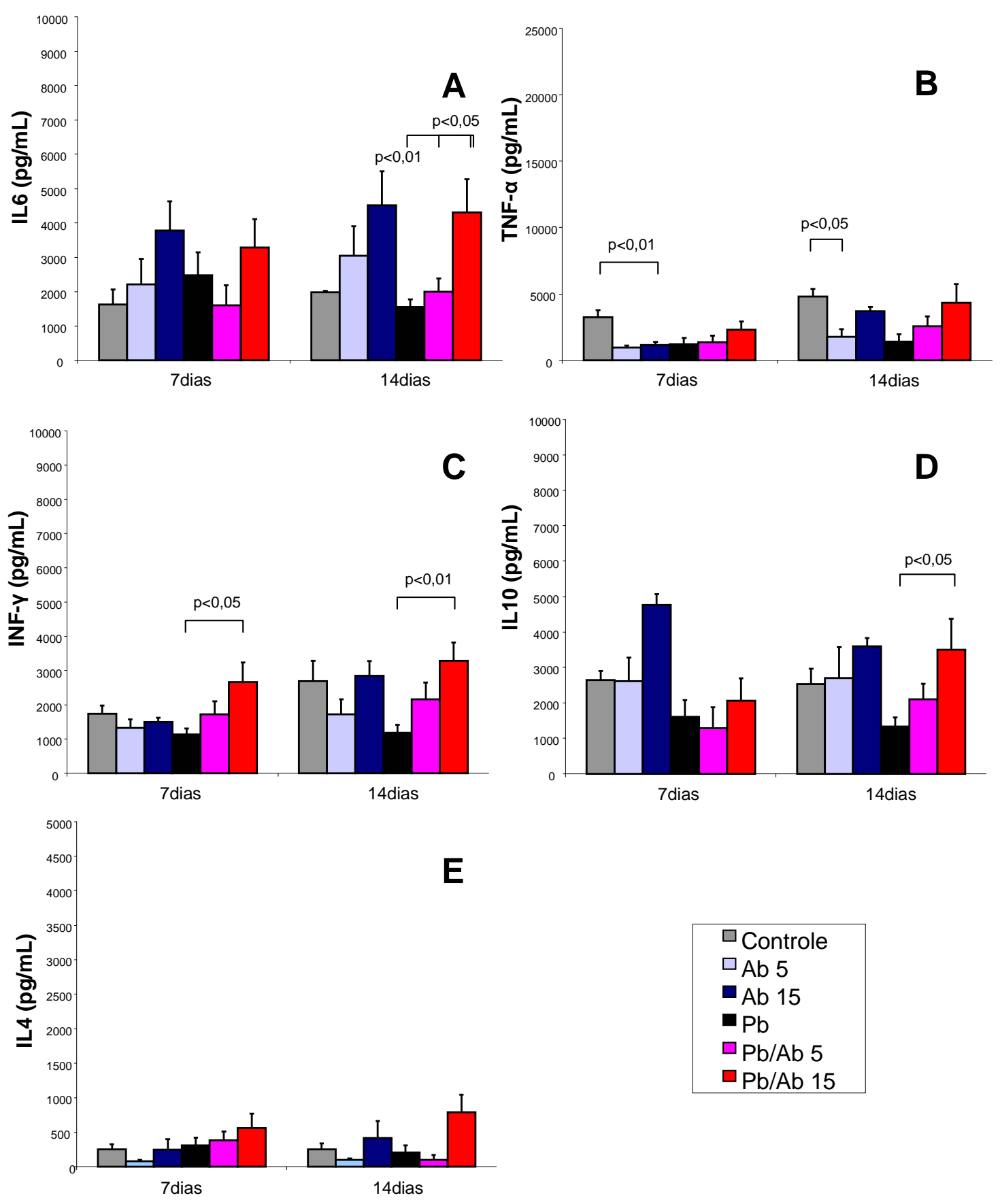

Figura 12 - Determinação de IL-6 (A), TNFa (B), INF-y (C), IL10 (D) e IL4 (E) nos sobrenadantes do fígado de camundongos normais ou infectados com $P$. brasiliensis, tratados com ração convencional (Controle e $\mathrm{Pb}$ ) ou suplementada com cogumelo $A$. blazei à $5 \%$ ( $\mathrm{Ab} 5 \mathrm{e}$ $\mathrm{Pb} / \mathrm{Ab} 5$ ) ou 15\% (Ab 15 e $\mathrm{Pb} / \mathrm{Ab} 15)$. As avaliações foram realizadas após 7 e 14 dias de infecção pelo método de ELISA. Dados são expressos com média \pm erro padrão $(n=8)$. 
Discussão 


\section{VIII - Discussão}

O uso popular de cogumelos medicinais baseia-se na premissa de que alguns de seus compostos atuam como agentes imunoestimulantes, fortalecendo os mecanismos de defesa do hospedeiro. As evidências experimentais de que produtos isolados do cogumelo $A$. blazei conferem proteção contra o desenvolvimento de neoplasias através da estimulação de mecanismos celulares de defesa [64] [83] [84], levaram-nos a hipotetisar que essa atividade imunomoduladora poderia aumentar a imunidade contra agentes infecciosos que sejam combatidos por esses mecanismos de defesa. Assim, observamos previamente que polissacarídeos isolados de $A$. blazei são capazes de modular positivamente a atividade de macrófagos aumentando sua capacidade fungicida e a produção de $\mathrm{H}_{2} \mathrm{O}_{2}$ [73]. No presente estudo, utilizamos o modelo de infecção experimental murina com o $P$. brasiliensis para avaliar o potencial do $A$. blazei como adjuvante no tratamento dessa micose profunda.

As concentrações de 5 e 15\% de cogumelo acrescentadas a ração correspondem a um consumo aproximado de 1 a $3 g$ de cogumelo/dia. A ausência de mudanças no consumo médio diário e consumo total de ração (Fig 2), indicam que a introdução do cogumelo na composição dietética, mesmo em concentração tão elevada quanto $15 \%$, não interfere na palatabilidade do alimento. Como esperado, observamos redução do ganho de peso associado à infecção, porém para nossa surpresa, aqueles infectados e tratados com ração com $15 \%$ de $A$. blazei apresentaram o maior nível de perda de massa corpórea, ainda que o consumo tenha sido similar ao dos demais grupos. Visto que a concentração protéica da ração de base é de $23,00 \%$ e o cogumelo apresenta $13,46 \%$ de proteínas em sua constituição [67] [85], a substituição de 15\% da mistura original 
da ração por cogumelo bruto representaria perda de apenas $1,33 \%$ na ingestão de proteínas, indicando que a redução de massa corpórea não decorre de um desequilíbrio protéico-calórico. Esse ponto de vista é reforçado pela não redução nos níveis séricos de proteínas totais desses animais que, na realidade, tenderam a ser superiores aos dos animais normais. Visto que esse pequeno aumento nos níveis de proteínas parece estar associado à infecção, deve ser considerada também a possibilidade de que reflitam a secreção de proteínas de fase aguda como a amilase plasmática aumentada na PCM aguda [86] ou a proteína reativa de fase aguda (PCR), comumente aumentada em processos infecciosos [87]. Descartamos a hipótese de que a suplementação nesse nível tivesse induzido aceleração do metabolismo dos animais, visto que as funções renais e hepáticas bem como os níveis de glicose dos animais não infectados e alimentados com rações suplementadas não sofreram alterações relevantes.

Os níveis de colesterol e triglicerídeos mostram-se mais elevados animais infectados, com ligeira diminuição nos animais tratados com $5 \%$ de cogumelo, sendo que a suplementação com $15 \%$ não exerceu o mesmo efeito. O colesterol é essencial para que o sistema imune funcione adequadamente e experimentos com animais têm demonstrado que as células do sistema imune dependem de componente de membrana plasmática para combater infecções. Assim, o LDL liga-se diretamente e desativa toxinas bacterianas, evitando que elas causem danos ao organismo. Em resumo, a elevação dos níveis de colesterol indicam que o organismos está sob algum processo de agressão e esse esterol funciona como um agente reparador, retornando aos níveis de normalidade após a resolução do processo [88]. Deve ser ressaltado que diferentemente do que acreditam muitos usuários, a suplementação dietética com $A$. blazei não foi capaz 
de reduzir os níveis séricos de glicose nem de colesterol ou triglicerídeos nos animais não infectados.

Os parâmetros de função renal não foram alterados pela inclusão do cogumelo na dieta, dados estes que corroboram os achados de Barbisan et al., [89] de que a administração do cogumelo não provoca mudanças na diurese dos animais. Os parâmetros de função hepática mostram que houve um aumento nos níveis de bilirrubina mas não das transaminases (AST e ALT), o que é compatível com os achados prévios de que o cogumelo pode ter um efeito hepatoprotetor contra lesões provocadas por agentes carcinogênicos [89] [90] [91] [92]. Outros estudos indicam que o extrato aquoso de Agaricus sylvaticus não induz alterações bioquímicas ou histopatológicas significativas em ratos normais [93].

Assim, os níveis elevados de bilirrubinas nos animais tratados com $15 \%$ de Agaricus blazei, podem estar relacionado com o aumento do TNF- $\alpha$, cuja elevação é classicamente associada a quadros de caquexia, que por sua vez pode levar a um aumento nos parâmetros de função hepática.

Em relação ao efeito da ração suplementada sobre a infecção propriamente dita, tivemos um resultado inesperado, particularmente na primeira semana de infecção em que se observou aumento da recuperação de fungos viáveis no pulmão. Em uma tentativa de explicar esse resultado, procuramos estabelecer associações com o padrão de citocinas liberado nesse órgão nesse período da infecção.

Os resultados indicam que, nesse período, a infecção induziu discreto aumento dos níveis de TNF- $\alpha$ nos pulmões, em comparação com os controles normais, porém, sem efeito significante do tratamento. Esperávamos que a 
infecção per se, fosse capaz de estimular a produção de TNF- $\alpha$, uma vez que essa citocina é produzida em resposta à parede celular do fungo e sugere-se que as cepas de $P$. brasiliensis que apresentam maior quantidade de $\beta$-glucana na parede celular induzem esse processo com maior intensidade [32] [94]. De fato, monócitos humanos incubados in vitro com o fungo liberam TNF, cujos níveis dependem das concentrações de $\beta$-glucanas presentes na parede da cepa utilizada [95]. Entretanto, nessa fase mais precoce, o tratamento com cogumelo não foi capaz de estimular a produção do TNF. Tal resultado foi inesperado uma vez que estudos prévios relatam que a ingestão do cogumelo, rico em $\beta$-glucana, estimula macrófagos e induz a secreção de TNF $\alpha$, IL8 e NO [69]. Assim, não observamos um efeito sinérgico do efeito das $\beta$-glucanas provenientes do agente infecciosos e do cogumelo usado na suplementação, sobre a produção de TNF.

O TNF é uma citocina essencial para o processo de ativação de macrófagos com consequente destruição do $P$. brasiliensis. Camundongos resistentes à infecção pelo $P$. brasiliensis mostram produção elevada de TNF- $\alpha$, que determina diminuição da carga fúngica [96] [97]. Em monócitos humanos e macrófagos murinos a estimulação com TNF resulta em aumento da capacidade de destruir o fungo via liberação de $\mathrm{H}_{2} \mathrm{O}_{2}$ ou $\mathrm{NO}$ [29] [27]. Assim, embora a infecção tivesse induzido pequeno aumento nos níveis de TNF, essa produção não foram suficientes para promover ativação celular, visto que a produção de IFN- $\gamma$ também foi baixa nesse período.

Chama a atenção o fato de que o tratamento, ao contrário do que esperávamos, exacerbou o nível de infecção dos animais, determinando a morte de três dos animais infectados (1 no grupo $\mathrm{Pb} / \mathrm{Ab} 5$ e 2 no grupo $\mathrm{Pb} / \mathrm{Ab}$ 15). Observamos previamente que a fração polissacarídica de A. blazei estimula a 
expressão de receptores de manose (MR) na superfície de macrófagos periotoniais murinos [73]. O MR é um dos receptores de reconhecimento de padrões (PRR) utilizado por fagócitos não-estimulados a promover a fagocitose de microrganismos [98] e sua expressão é gradualmente reduzida pela ativação celular por IFN- $\gamma$ [99]. Observamos, mais recentemente, que a exposição in vitro de monócitos humanos a essa fração polissacarídica (rica em $\beta$-glucanas) aumenta a expressão de receptores Toll-símiles TLR-2 e TLR-4 [100]. O TLR-4 é o receptor chave de lipopolissacarídeos [101] e observa-se que animais que expressam esse receptor são mais suscetíveis a ação deletéria do LPS que aqueles deficientes de TRL-4 [43], provavelmente pela produção exacerbada de NO [20]. Estudos in vitro demonstraram que a interação de macrófagos com $P$. brasiliensis via TRL-4 resulta na ativação dessas células com aumento da fagocitose e produção de NO, IL-12 e MCP-1. Tal ativação, entretanto, mostra associação com maior número de fungos viáveis nos macrófagos infectados.

O TRL-2, por sua vez é um receptor de peptideoglicanos e lipoproteínas [102] e poderiam servir de vias de ativação inespecífica dos macrófagos, uma vez que o cogumelo é rico também em peptideoglicanos [63]. Assim, é possível que a suplementação dietética, logo no início da infecção, tenha induzido aumento na expressão desses receptores, com consequente aumento na atividade fagocítica dos macrófagos alveolares. Visto que a produção de TNF- $\alpha$ e IFN- $\gamma$ ainda era baixa nesse período, tais células não estavam adequadamente ativadas, permitindo a permanência de fungos vivos em seu interior. Ao mesmo tempo, a intensa redução nos níveis de IL-10 facilitaria a produção de NO e IL-12 por esses macrófagos. Assim, esse resultado corrobora a hipótese de que a exacerbação da atividade fagocítica por macrófagos por via independente de IFN- $\gamma$, facilita 0 
escape do $P$. brasiliensis da ação de neutrófilos, favorecendo o estabelecimento da infecção e o desenvolvimento de uma forma mais grave da doença [20].

A análise dos parâmetros de resposta imune e infecção aos 14 dias, mostra um perfil diferente do obtido na primeira semana. Enquanto os controles de infecção (grupo $\mathrm{Pb}$ ) mostraram aumento significante da carga fúngica em relação ao período inicial, a inclusão de $5 \%$ do cogumelo na dieta reduziu drasticamente o número de fungos viáveis no pulmão. Diferentemente do que se observou na fase mais precoce da infecção, aos 14 dias há aumento significante dos níveis de TNF nos pulmão, paralelamente à redução dos níveis de IL-4. Além disso, embora o pulmão não apresente alterações significantes nos níveis de IFN, observa-se que o tratamento com cogumelo aumenta a produção dessa citocina no baço. Assim, é possível que nesse período, os macrófagos alveolares previamente ativados pelas TLR ou MR, ou macrófagos pré-ativados no baço e infiltrados no pulmão, estejam produzindo TNF- $\alpha$ em concentração suficiente para promover o combate ao fungo.

Não detectamos fungos viáveis nos outros órgãos avaliados, o que não nos permite estabelecer associações com o padrão de citocinas liberado nesses locais. No entanto é interessante notar que no baço, diferentemente do que ocorreu no pulmão, o tratamento com o cogumelo induziu um aumento na produção de IFN e de TNF desde o início da infecção, mostrando uma compartimentalização da resposta imune durante a infecção com o Pb.

A visão de que a suplementação dietética pode ter trazido algum benefício aos animais infectados é reforçada pela observação de seu efeito sobre a atividade linfoproliferativa. Esse é um parâmetro clássico de avaliação do potencial de resposta imune celular e observamos que os animais infectados tem 
uma depressão da resposta ao mitógeno Con A. Essa depressão é tradicionalmente relatada e discutida na PCM [103] e pode ser explicada, entre outras razões, pela falha na apresentação antigênica. Assim, a incubação de linfócitos com $P$. brasiliensis ou gp 43 purificada leva à diminuição na expressão de moléculas MHC de classe II em células dendríticas imaturas ou ainda interfere na maturação dessas células induzida por LPS. Outros trabalhos relatam expressão inadequada de moléculas coestimuladoras, apoptose de células $T$, geração de citocinas supressoras como a IL-10, entre alguns outros processos [103]. No presente estudo, é possível pensar que o aumento nos níveis esplênicos de IL-10 no período de 7 dias, possa ter contribuído, pelo menos parcialmente, para a inibição da resposta proliferativa, a despeito da produção local de IFN- $\gamma$.

Essa capacidade de resposta sofre discreta recuperação na segunda semana e, como esperado, observa-se que a suplementação nutricional facilita esse processo de recuperação. Essa observação é compatível com estudos prévios relatando que polissacarídeos do cogumelo Coriolus versicolor são capazes de aumentar a resposta de esplenócitos a mitógenos tanto após o tratamento in vivo quanto por sua adição à cultura [104]. Polissacarídeos do cogumelo Flammulina velutipes administradas i.p. em camundongos, também foram capazes de induzir a proliferação de linfócitos esplênicos [105].

Em resumo, nossos resultados sustentam parcialmente nossa hipótese inicial, indicando que a suplementação ajuda os animais a restabelecerem sua resposta imune celular, como indicado pela restauração da atividade linfoproliferativa e pelo perfil de citocinas na segunda semana e pela redução no número de UFCs isoladas do pulmão na segunda semana. Entretanto, o 
cogumelo, quando em excesso (15\%) ou se administrado no início da fase aguda, pode facilitar a instalação do agente infeccioso e determinar o estabelecimento de uma doença mais grave. Assim, sugerimos que o cogumelo estimula inicialmente os mecanismos inespecíficos de defesa, facilitando a fagocitose do fungo. Como essas células ainda não se encontram ativadas, há uma facilitação da permanência das leveduras nos pulmões, bem como o desenvolvimento de resposta aguda intensa e morte de alguns dos animais. A continuidade do tratamento parece, então, favorecer o estabelecimento de uma resposta imune celular eficaz, tornando os animais sobreviventes em melhores condições de resistir à infecção. Desse modo, é possível que a suplementação nutricional possa ser usada como adjuvante no tratamento da infecção crônica, hipótese que merece ser futuramente testada. 
Referências Bibliográficas 


\section{IX - Referências Bibliográficas}

[1] Brummer E, Castaneda E, Restrepo A. Paracoccidioidomycosis: an update. Clinical microbiology reviews. 1993 Apr;6(2):89-117.

[2] San-Blás F S-BG. Paracoccidioides brasiliensis. Szaniszlo PJ Fungal Dimorphism New York: Plenum. 1985.

[3] Carbonell LM RJ. Tranformation of mycelial and yeast forms of Paracoccidioides brasiliensis in cultures and experimental inoculations. J Bacteriol. 1965;90.

[4] San-Blas G, Nino-Vega G, Iturriaga T. Paracoccidioides brasiliensis and paracoccidioidomycosis: molecular approaches to morphogenesis, diagnosis, epidemiology, taxonomy and genetics. Med Mycol. 2002 Jun;40(3):225-42.

[5] San-Blás F S-BG, Inlow D. Dimorphism in Paracoccidioides brasiliensis. Zentralbl Bakteriol. 1980:6.

[6] Paris S, Duran-Gonzalez S, Mariat F. Nutritional studies on Paracoccidioides brasiliensis: the role of organic sulfur in dimorphism. Sabouraudia. 1985 Apr;23(2):85-92.

[7] Restrepo A, Salazar ME, Cano LE, Stover EP, Feldman D, Stevens DA. Estrogens inhibit mycelium-to-yeast transformation in the fungus Paracoccidioides brasiliensis: implications for resistance of females to paracoccidioidomycosis. Infection and immunity. $1984 \mathrm{Nov} ; 46(2): 346-53$.

[8] Salazar ME, Restrepo A, Stevens DA. Inhibition by estrogens of conidiumto-yeast conversion in the fungus Paracoccidioides brasiliensis. Infection and immunity. 1988 Mar;56(3):711-3.

[9] Loose DS, Stover EP, Restrepo A, Stevens DA, Feldman D. Estradiol binds to a receptor-like cytosol binding protein and initiates a biological response in Paracoccidioides brasiliensis. Proceedings of the National Academy of Sciences of the United States of America. 1983 Dec;80(24):7659-63.

[10] Stover EP, Schar G, Clemons KV, Stevens DA, Feldman D. Estradiolbinding proteins from mycelial and yeast-form cultures of Paracoccidioides brasiliensis. Infection and immunity. 1986 Jan;51(1):199-203.

[11] Wanke B. LA. Epidemiologyand and paracoccidioidomycosis infection. In: Franco M, Lacaz CS, Restrepo- Moreno A, Del Negro GParacoccidioidomycosis Boca raton: CRC Press. 1994.

[12] McEwen JG, Bedoya V, Patino MM, Salazar ME, Restrepo A. Experimental murine paracoccidiodomycosis induced by the inhalation of conidia. $J$ Med Vet Mycol. 1987 Jun;25(3):165-75.

[13] Oliveira SJ, Mamoni RL, Musatti CC, Papaiordanou PM, Blotta MH. Cytokines and lymphocyte proliferation in juvenile and adult forms of paracoccidioidomycosis: comparison with infected and non-infected controls. Microbes and infection / Institut Pasteur. 2002 Feb;4(2):139-44.

[14] Franco M MR, Moscardi-Bacchi M, Rezkallah-Iwasso MT, Montenegro MR. . Paracoccidiodomycosis. . Bailliere's Clin Trp Med Commun Dis. 1989;4.

[15] Mendes RP. The gamut of clinical manifestations. . In: Franco M, Lacaz CS, Restrepo-Moreno A, Del Negro G, editors Paracoccidioidomycosis Boca raton: CRC Press. 1994:233-58.

[16] Franco M, Peracoli MT, Soares A, Montenegro R, Mendes RP, Meira DA. Host-parasite relationship in paracoccidioidomycosis. Current topics in medical mycology. 1993;5:115-49. 
[17] Calich VLG RM, Vaz CAC, Burger E, Singer-Vermes LM. Resistance mechanism to experimental Paracoccidioides brasiliensis infection. . Cienc Cult. 1994;46.

[18] Musatti CC PM, Soares AMVC, Rezkallah-Iwasso MT. In: Franco MF, Lacaz CS, Restrepo A, Del Negro G. . Cell-mediated immunity in patients with paracoccidiodomycosis. Paracoccidiodomycosis Flórida, USA: CRC Press; . 1994.

[19] Peraçoli MTS P-FM, Pereira da Silva MF, Montenegro MR. . Natural killer cell activity in experimental paracoccidiodomycosis of the Syrian hamster. . Rev Inst Med Trop São Paulo. 1995; 37.

[20] Calich VL, da Costa TA, Felonato M, Arruda C, Bernardino S, Loures FV, et al. Innate immunity to Paracoccidioides brasiliensis infection. Mycopathologia. 2008 Apr-May;165(4-5):223-36.

[21] Brummer E, Hanson LH, Restrepo A, Stevens DA. Intracellular multiplication of Paracoccidioides brasiliensis in macrophages: killing and restriction of multiplication by activated macrophages. Infection and immunity. 1989 Aug;57(8):2289-94.

[22] Cano LE, Brummer E, Stevens DA, Restrepo A. Fate of conidia of Paracoccidioides brasiliensis after ingestion by resident macrophages or cytokinetreated macrophages. Infection and immunity. 1992 May;60(5):2096-100.

[23] Cano LE, Arango R, Salazar ME, Brummer E, Stevens DA, Restrepo A. Killing of Paracoccidioides brasiliensis conidia by pulmonary macrophages and the effect of cytokines. J Med Vet Mycol. 1992;30(2):161-8.

[24] Moscardi-Bacchi M, Brummer E, Stevens DA. Support of Paracoccidioides brasiliensis multiplication by human monocytes or macrophages: inhibition by activated phagocytes. Journal of medical microbiology. 1994 Mar;40(3):159-64.

[25] Calvi SA, Peracoli MT, Mendes RP, Marcondes-Machado J, Fecchio D, Marques SA, et al. Effect of cytokines on the in vitro fungicidal activity of monocytes from paracoccidioidomycosis patients. Microbes and infection / Institut Pasteur. 2003 Feb;5(2):107-13.

[26] Carmo JPM PM, Calvi SA, Dias- Melicio LA, Tavian EG, Soares, AMVC. . Role of granulocyte- macrophage colony-stimulating factor (GM-CSF) on human monocytes activation in vitro for high virulent Paracoccidioides brasiliensis killing. . Annual Review of Biomedical Sciences Special Issue. 2002.

[27] Carmo JP, Dias-Melicio LA, Calvi SA, Peracoli MT, Soares AM. TNF-alpha activates human monocytes for Paracoccidioides brasiliensis killing by an $\mathrm{H} 2 \mathrm{O} 2-$ dependent mechanism. Med Mycol. 2006 Jun;44(4):363-8.

[28] Gonzalez A, de Gregori W, Velez D, Restrepo A, Cano LE. Nitric oxide participation in the fungicidal mechanism of gamma interferon-activated murine macrophages against Paracoccidioides brasiliensis conidia. Infection and immunity. 2000 May;68(5):2546-52.

[29] Moreira AP, Dias-Melicio LA, Peracoli MT, Calvi SA, Victoriano de Campos Soares AM. Killing of Paracoccidioides brasiliensis yeast cells by IFN-gamma and TNF-alpha activated murine peritoneal macrophages: evidence of $\mathrm{H}(2) \mathrm{O}(2)$ and NO effector mechanisms. Mycopathologia. 2008 Jul;166(1):17-23.

[30] Dunn PL, North RJ. Early gamma interferon production by natural killer cells is important in defense against murine listeriosis. Infection and immunity. 1991 Sep;59(9):2892-900.

[31] Levitz SM, North EA. gamma Interferon gene expression and release in human lymphocytes directly activated by Cryptococcus neoformans and Candida albicans. Infection and immunity. 1996 May;64(5):1595-9. 
[32] Figueiredo F, Alves LM, Silva CL. Tumour necrosis factor production in vivo and in vitro in response to Paracoccidioides brasiliensis and the cell wall fractions thereof. Clinical and experimental immunology. 1993 Aug;93(2):189-94.

[33] Anjos AR, Calvi SA, Ferracini R, Peracoli MT, Silva CL, Soares AM. Role of Paracoccidioides brasiliensis cell wall fraction containing beta-glucan in tumor necrosis factor-alpha production by human monocytes: correlation with fungicidal activity. Med Mycol. 2002 Aug;40(4):377-82.

[34] Restrepo A, Restrepo M, de Restrepo F, Aristizabal LH, Moncada LH, Velez $\mathrm{H}$. Immune responses in paracoccidioidomycosis. A controlled study of 16 patients before and after treatment. Sabouraudia. 1978 Jun;16(2):151-63.

[35] Mota NG, Rezkallah-Iwasso MT, Peracoli MT, Audi RC, Mendes RP, Marcondes J, et al. Correlation between cell-mediated immunity and clinical forms of paracoccidioidomycosis. Transactions of the Royal Society of Tropical Medicine and Hygiene. 1985;79(6):765-72.

[36] Peraçoli MTS SA, Mendes RP, Marques AS, Guastale HA et al. Cellmediated immunity in patients with the chronic form of paracoccidiodomycosis. Early and late evaluation after treatment. Rev Iber Micol 1988;5:69.

[37] Benard G, Durandy A, Assis CM, Hong MA, Orii NM, Sato MN, et al. Responses of $\mathrm{T}$ and $\mathrm{B}$ lymphocytes to a Paracoccidioides brasiliensis cell wall extract in healthy sensitized and nonsensitized subjects. The American journal of tropical medicine and hygiene. 1995 Aug;53(2):189-94.

[38] Benard G, Hong MA, Del Negro GM, Batista L, Shikanai-Yasuda MA, Duarte AJ. Antigen-specific immunosuppression in paracoccidioidomycosis. The American journal of tropical medicine and hygiene. 1996 Jan;54(1):7-12.

[39] Benard G, Mendes-Giannini MJ, Juvenale M, Miranda ET, Duarte AJ. Immunosuppression in paracoccidioidomycosis: T cell hyporesponsiveness to two Paracoccidioides brasiliensis glycoproteins that elicit strong humoral immune response. The Journal of infectious diseases. 1997 May;175(5):1263-7.

[40] Castaneda E, Brummer E, Pappagianis D, Stevens DA. Impairment of cellular but not humoral immune responses in chronic pulmonary and disseminated paracoccidioidomycosis in mice. Infection and immunity. 1988 Jul;56(7):1771-7.

[41] Fazioli Rdos A, Singer-Vermes LM, Kashino SS, Burger E, De Franco MF, Moscardi-Bacchi $M$, et al. Delayed-type hypersensitivity response in an isogenic murine model of paracoccidioidomycosis. Mycopathologia. 1994 Jun;126(3):13746.

[42] Arango M, Yarzabal L. T-cell dysfunction and hyperimmunoglobulinemia $E$ in paracoccidioidomycosis. Mycopathologia. 1982 Aug 20;79(2):115-23.

[43] Calich VL, Singer-Vermes LM, Siqueira AM, Burger E. Susceptibility and resistance of inbred mice to Paracoccidioides brasiliensis. British journal of experimental pathology. 1985 Oct;66(5):585-94.

[44] Cano LE, Singer-Vermes LM, Vaz CA, Russo M, Calich VL. Pulmonary paracoccidioidomycosis in resistant and susceptible mice: relationship among progression of infection, bronchoalveolar cell activation, cellular immune response, and specific isotype patterns. Infection and immunity. 1995 May;63(5):1777-83.

[45] Baida H, Biselli PJ, Juvenale M, Del Negro GM, Mendes-Giannini MJ, Duarte AJ, et al. Differential antibody isotype expression to the major Paracoccidioides brasiliensis antigen in juvenile and adult form paracoccidioidomycosis. Microbes and infection / Institut Pasteur. 1999 Apr;1(4):273-8. 
[46] Mamoni RL, Nouer SA, Oliveira SJ, Musatti CC, Rossi CL, Camargo ZP, et al. Enhanced production of specific $\lg G 4, \lg E, \lg A$ and TGF-beta in sera from patients with the juvenile form of paracoccidioidomycosis. Med Mycol. 2002 Apr;40(2):153-9.

[47] Benard G, Romano CC, Cacere CR, Juvenale M, Mendes-Giannini MJ, Duarte AJ. Imbalance of IL-2, IFN-gamma and IL-10 secretion in the immunosuppression associated with human paracoccidioidomycosis. Cytokine. 2001 Feb 21;13(4):248-52.

[48] Mello LM S-VM, Junior VR. . Patients with active infection with Paracoccidioides brasiliensis present a $\mathrm{TH} 2$ immune response characterized by high interleukin-4 and interleukin-5 production. . Hum Immunol. 2002;63.

[49] Romano CC, Mendes-Giannini MJ, Duarte AJ, Benard G. IL-12 and neutralization of endogenous IL-10 revert the in vitro antigen-specific cellular immunosuppression of paracoccidioidomycosis patients. Cytokine. 2002 May 7;18(3):149-57.

[50] Romano CC, Mendes-Giannini MJ, Duarte AJ, Benard G. The role of interleukin-10 in the differential expression of interleukin-12p70 and its beta2 receptor on patients with active or treated paracoccidioidomycosis and healthy infected subjects. Clinical immunology (Orlando, Fla. 2005 Jan;114(1):86-94.

[51] de Almeida SR, de Moraes JZ, de Camargo ZP, Gesztesi JL, Mariano M, Lopes JD. Pattern of immune response to GP43 from Paracoccidioides brasiliensis in susceptible and resistant mice is influenced by antigen-presenting cells. Cellular immunology. 1998 Nov 25;190(1):68-76.

[52] Calich VL, Kashino SS. Cytokines produced by susceptible and resistant mice in the course of Paracoccidioides brasiliensis infection. Brazilian journal of medical and biological research $=$ Revista brasileira de pesquisas medicas $\mathrm{e}$ biologicas / Sociedade Brasileira de Biofisica [et al. 1998 May;31(5):615-23.

[53] Kashino SS FR, Cafalli-Favati C, Meloni-Bruneri LH, Vaz CA, Burger E, et al. - Paracoccidioides brasiliensis infection is linked to a preferential Th1 immune response, whereas susceptibility is associated with absence of INF-gamma production. . J Interferon Cytokine Res. 2000;20.

[54] Livonesi MC, Souto JT, Campanelli AP, Maffei CM, Martinez R, Rossi MA, et al. Deficiency of IL-12p40 subunit determines severe paracoccidioidomycosis in mice. Med Mycol. 2008 Nov;46(7):637-46.

[55] Cavassani KA, Campanelli AP, Moreira AP, Vancim JO, Vitali LH, Mamede $\mathrm{RC}$, et al. Systemic and local characterization of regulatory $\mathrm{T}$ cells in a chronic fungal infection in humans. J Immunol. 2006 Nov 1;177(9):5811-8.

[56] Cacere CR, Mendes-Giannini MJ, do Valle AC, Duarte AJ, Benard G. Altered ex vivo expression of caspase 8, caspase 9, and Bcl-2 is associated with T-cell hyporeactivity in patients with paracoccidioidomycosis. Clin Vaccine Immunol. 2009 Jun;16(6):953-5.

[57] Campanelli AP, Martins GA, Souto JT, Pereira MS, Livonesi MC, Martinez $\mathrm{R}$, et al. Fas-Fas ligand (CD95-CD95L) and cytotoxic $\mathrm{T}$ lymphocyte antigen-4 engagement mediate $T$ cell unresponsiveness in patients with paracoccidioidomycosis. The Journal of infectious diseases. 2003 May 1;187(9):1496-505.

[58] Bhaskaram P. Micronutrient malnutrition, infection, and immunity: an overview. Nutrition reviews. 2002 May;60(5 Pt 2):S40-5.

[59] Borchers AT, Stern JS, Hackman RM, Keen CL, Gershwin ME. Mushrooms, tumors, and immunity. Proceedings of the Society for Experimental 
Biology and Medicine Society for Experimental Biology and Medicine (New York, NY. 1999 Sep;221(4):281-93.

[60] Vicent EC OV, Lui F. . A review of pharmacological activities of mushrooms polysaccharides. . Int J Med Mushr. 1999;1.

[61] Chang R. Functional properties of edible mushrooms. Nutrition reviews. 1996 Nov;54(11 Pt 2):S91-3.

[62] Takaku T, Kimura Y, Okuda $\mathrm{H}$. Isolation of an antitumor compound from Agaricus blazei Murill and its mechanism of action. The Journal of nutrition. 2001 May;131(5):1409-13.

[63] Mizuno T HT, Nakamura T, Ito H, Shimura K, Sumiya T. et al. . Antitumor activity and some properties of water-soluble polysaccharides from Himematisutake, the fruiting body of Agaricus blazei Murrill. . Agricult Biol Chem. 1990;54.

[64] Kidd PM. The use of mushroom glucans and proteoglycans in cancer treatment. Altern Med Rev. 2000 Feb;5(1):4-27.

[65] Kaneno R, Fontanari LM, Santos SA, Di Stasi LC, Rodrigues Filho E, Eira AF. Effects of extracts from Brazilian sun-mushroom (Agaricus blazei) on the NK activity and lymphoproliferative responsiveness of Ehrlich tumor-bearing mice. Food Chem Toxicol. 2004 Jun;42(6):909-16.

[66] Ito $H$, Shimura $K$, Itoh $H$, Kawade $M$. Antitumor effects of a new polysaccharide-protein complex (ATOM) prepared from Agaricus blazei (Iwade strain 101) "Himematsutake" and its mechanisms in tumor-bearing mice. Anticancer research. 1997 Jan-Feb;17(1A):277-84.

[67] Ebina T, Fujimiya Y. Antitumor effect of a peptide-glucan preparation extracted from Agaricus blazei in a double-grafted tumor system in mice. Biotherapy (Dordrecht, Netherlands). 1998;11(4):259-65.

[68] Kuo YC, Huang YL, Chen CC, Lin YS, Chuang KA, Tsai WJ. Cell cycle progression and cytokine gene expression of human peripheral blood mononuclear cells modulated by Agaricus blazei. The Journal of laboratory and clinical medicine. 2002 Sep;140(3):176-87.

[69] Sorimachi K, Akimoto K, Ikehara Y, Inafuku K, Okubo A, Yamazaki S. Secretion of TNF-alpha, IL-8 and nitric oxide by macrophages activated with Agaricus blazei Murill fractions in vitro. Cell structure and function. 2001 Apr;26(2):103-8.

[70] Nakajima A, Ishida T, Koga M, Takeuchi T, Mazda O, Takeuchi M. Effect of hot water extract from Agaricus blazei Murill on antibody-producing cells in mice. International immunopharmacology. 2002 Jul;2(8):1205-11.

[71] Fujimiya Y, Suzuki Y, Oshiman K, Kobori H, Moriguchi K, Nakashima H, et al. Selective tumoricidal effect of soluble proteoglucan extracted from the basidiomycete, Agaricus blazei Murill, mediated via natural killer cell activation and apoptosis. Cancer Immunol Immunother. 1998 May;46(3):147-59.

[72] Zhong M, Tai A, Yamamoto I. In vitro augmentation of natural killer activity and interferon-gamma production in murine spleen cells with Agaricus blazei fruiting body fractions. Bioscience, biotechnology, and biochemistry. 2005 Dec;69(12):2466-9.

[73] Martins PR, Gameiro MC, Castoldi L, Romagnoli GG, Lopes FC, Pinto AV, et al. Polysaccharide-rich fraction of Agaricus brasiliensis enhances the candidacidal activity of murine macrophages. Memorias do Instituto Oswaldo Cruz. 2008 May;103(3):244-50. 
[74] MC. G. Efeito imunomodulador de Agaricus blazei ss. Heinem. Na infecção experimental com Paracoccidioides brasiliensis. [dissertação] Botucatu: Faculdade de Medicina, Universidade Estadual Paulista. 2006.

[75] Mizuno T, Kinoshita T, Zhuang C, Ito H, Mayuzumi Y. Antitumor-active heteroglycans from niohshimeji mushroom, Tricholoma giganteum. Bioscience, biotechnology, and biochemistry. 1995 Apr;59(4):568-71.

[76] Wasser SP, Weis AL. Therapeutic effects of substances occurring in higher Basidiomycetes mushrooms: a modern perspective. Critical reviews in immunology. 1999;19(1):65-96.

[77] Ooi VE, Liu F. Immunomodulation and anti-cancer activity of polysaccharide-protein complexes. Current medicinal chemistry. 2000 Jul;7(7):715-29.

[78] Mota V. Bioquímica Clínica para Laboratório - Princípios e Interpretações. 2003;4 edição.

[79] Soares AM, Calvi SA, Peracoli MT, Fernandez AC, Dias LA, Dos Anjos AR. Modulatory effect of prostaglandins on human monocyte activation for killing of high- and low-virulence strains of Paracoccidioides brasiliensis. Immunology. 2001 Apr;102(4):480-5.

[80] Firenzuoli F, Gori L, Lombardo G. The Medicinal Mushroom Agaricus blazei Murrill: Review of Literature and Pharmaco-Toxicological Problems. Evid Based Complement Alternat Med. 2008 Mar;5(1):3-15.

[81] Kurita N, Sano A, Coelho KI, Takeo K, Nishimura K, Miyaji M. An improved culture medium for detecting live yeast phase cells of Paracoccidioides brasiliensis. J Med Vet Mycol. 1993;31(3):201-5.

[82] Puccia R, Schenkman S, Gorin PA, Travassos LR. Exocellular components of Paracoccidioides brasiliensis: identification of a specific antigen. Infection and immunity. 1986 Jul;53(1):199-206.

[83] Kawagishi $H$, Nomura A, Yumen T, Mizuno T, Hagiwara T, Nakamura T. Isolation and properties of a lectin from the fruiting bodies of Agaricus blazei. Carbohydrate research. 1988 Nov 15;183(1):150-4.

[84] Kaneno R. Role of natural killer cells in antitumor resistance. ARBS Ann Rev Biomed Sci. 2005;7.

[85] Gameiro MC. Efeito imunomodulador de Agaricus blazei ss. Heinem. Na infecção experimental com Paracoccidioides brasiliensis. [dissertação] Botucatu: Faculdade de Medicina, Universidade Estadual Paulista. 2006.

[86] Xidieh CF, Singer-Vermes LM, Calich VL, Burger E. Plasma amylase levels as a marker of disease severity in an isogenic murine model of paracoccidioidomycosis. J Med Vet Mycol. 1994;32(1):37-45.

[87] Marquez AS MA, Leonello PC, Nakanishi FA, Itano EM. Serum proteins and fractions, HDL-cholesterol and total $\lg G$ and $\lg E$ levels in cases of acute and chronic paracoccidioidomycosis. Rev Soc Bras Med Trop. 2009;42(3).

[88] Campbell-McBride N. Cholesterol - friend or enemy. Wise Traditions. 2007;8(3).

[89] Barbisan LF, Miyamoto M, Scolastici C, Salvadori DM, Ribeiro LR, Eira AF, et al. Influence of aqueous extract of Agaricus blazei on rat liver toxicity induced by different doses of diethylnitrosamine. Journal of ethnopharmacology. 2002 Nov;83(1-2):25-32.

[90] Ooi GC, Peh WC. Clinics in diagnostic imaging (14). Cavernous haemangioma of the liver. Singapore medical journal. 1996 Jun;37(3):312-4. 
[91] Ribeiro-Santos G, Barbisan LF, Lopes FC, Spinardi-Barbisan AL, da Eira AF, Kaneno R. Lack of chemopreventive activity of Agaricus blazei mushroom on the development of 1,2-dimethylhydrazine-induced colonic aberrant crypt foci in rats. Nutrition and cancer. 2008;60(6):768-75.

[92] HI EMB AA, Bach EE, Ogata TRP. Efeito protetor do extrato de Agaricus sylvaticus em fígado de ratos do tipo wistar inoculado com pristane. Saúde Coletiva. 2008;5(21).

[93] Novaes WRCG NL, Melo AL, Recova VL. Avaliação da toxicidade aguda do cogumelo Agaricus sylvaticus. Com Ciências Saúde. 2007;18(3).

[94] Silva CL, Alves LM, Figueiredo F. Involvement of cell wall glucans in the genesis and persistence of the inflammatory reaction caused by the fungus Paracoccidioides brasiliensis. Microbiology (Reading, England). $1994 \mathrm{May} ; 140$ ( Pt 5):1189-94.

[95] Kurokawa CS, Araujo JP, Jr., Soares AM, Sugizaki MF, Peracoli MT. Proand anti-inflammatory cytokines produced by human monocytes challenged in vitro with Paracoccidioides brasiliensis. Microbiology and immunology. 2007;51(4):421-8.

[96] Singer-Vermes LM, Ciavaglia MC, Kashino SS, Burger E, Calich VL. The source of the growth-promoting factor(s) affects the plating efficiency of Paracoccidioides brasiliensis. J Med Vet Mycol. 1992;30(3):261-4.

[97] Nascimento FR, Calich VL, Rodriguez D, Russo M. Dual role for nitric oxide in paracoccidioidomycosis: essential for resistance, but overproduction associated with susceptibility. J Immunol. 2002 May 1;168(9):4593-600.

[98] Ofek I, Goldhar J, Keisari Y, Sharon N. Nonopsonic phagocytosis of microorganisms. Annual review of microbiology. 1995;49:239-76.

[99] Martinez-Pomares L, Wienke D, Stillion R, McKenzie EJ, Arnold JN, Harris $\mathrm{J}$, et al. Carbohydrate-independent recognition of collagens by the macrophage mannose receptor. European journal of immunology. 2006 May;36(5):1074-82.

[100] Chow JC, Young DW, Golenbock DT, Christ WJ, Gusovsky F. Toll-like receptor-4 mediates lipopolysaccharide-induced signal transduction. The Journal of biological chemistry. 1999 Apr 16;274(16):10689-92.

[101] Kirschning CJ, Wesche H, Merrill Ayres T, Rothe M. Human toll-like receptor 2 confers responsiveness to bacterial lipopolysaccharide. The Journal of experimental medicine. 1998 Dec 7;188(11):2091-7.

[102] Benard G. An overview of the immunopathology of human paracoccidioidomycosis. Mycopathologia. 2008 Apr-May;165(4-5):209-21.

[103] Wang HX, Ng TB, Ooi VE, Liu WK, Chang ST. A polysaccharide-peptide complex from cultured mycelia of the mushroom Tricholoma mongolicum with immunoenhancing and antitumor activities. Biochemistry and cell biology = Biochimie et biologie cellulaire. 1996;74(1):95-100.

[104] Leung MY, Fung KP, Choy YM. The isolation and characterization of an immunomodulatory and anti-tumor polysaccharide preparation from Flammulina velutipes. Immunopharmacology. 1997 Jan;35(3):255-63. 
Anexos 
$\mathrm{X}-$ Anexo 1

Valores de Referência - Parâmetros Bioquímicos

\begin{tabular}{|c|c|}
\hline Analito & Intervalo de Referência \\
\hline ALT / TGP & $28-132 \mathrm{U} / \mathrm{L}$ \\
\hline AST / TGO & $59-247 \mathrm{U} / \mathrm{L}$ \\
\hline Uréia & $38.61-62.21 \mathrm{mg} / \mathrm{dL}$ \\
\hline Colesterol & $36-96 \mathrm{mg} / \mathrm{dL}$ \\
\hline Creatinina & $0.2-0.8 \mathrm{mg} / \mathbf{d L}$ \\
\hline Glicose & $90-192 \mathrm{mg} / \mathbf{d L}$ \\
\hline Bilirrubina & $0.1-0.9 \mathrm{mg} / \mathbf{d L}$ \\
\hline Proteína Total & $3.6-6.6 \mathrm{~g} / \mathrm{dL}$ \\
\hline Triglicérides & $55-144 \mathrm{mg} / \mathrm{dL}$ \\
\hline
\end{tabular}

